\title{
Power-law distribution in the external debt-to-fiscal revenue ratio: empirical evidence and a theoretical model
}

\author{
Gilles Dufrénot ${ }^{1}$, Anne-Charlotte Paret $^{2}$
}

\begin{abstract}
This paper provides evidence that the external debt-to-fiscal revenue ratio in the emerging countries follows a power-law distribution. Such a distribution reflects the fact that external debt distress or debt crises correspond to extreme events that have been found to happen fairly often. We formally test the hypothesis of a power-law, going further than the usual visual inspection of the distribution of the variable of interest on a doubly logarithmic scale. We further show that such a distribution can be derived from a theoretical model in which uncertainty comes from tax evasion and corruption. Using the framework of an optimal stochastic growth moc'el, we model the external debt-to-fiscal revenue ratio as a diffusion process for which the stochastic steady state distribution is derived using the properties of Itô diffusion processes.
\end{abstract}

Keywords: Power-law, stochastic growth, external debt, emerging countries.

JEL Classification: C14, C51, C61

\section{Introduction}

External debt distress and episodes of foreign debt crises have been recurrent in the emerging countries history, at least since the beginning 1980s.

\footnotetext{
${ }^{1}$ Corresponding author, Aix-Marseille Univ.(Aix-Marseille School of Economics, EHESS \& CNRS) and CEPII, Email: gilles.dufrenot@univ-amu.fr

${ }^{2}$ Aix-Marseille Univ.(Aix-Marseille School of Economics, EHESS \& CNRS) and Amundi AM, Email: anne-charlotte.paret@amundi.com
} 
They have taken different forms: tightened restrictions on access to international capital markets, accumulation of large stocks of financial liabilities, debt restructuring, bailouts packages provided by the international financial organizations, debt rescheduling, delays in paying debt service, strong increases in bond spreads, arrears of principal or interest on external obligations. The question regarding the policies designed to tackle sovereign debt crises has given rise to a voluminous literature. The issue is not only the ways out of debt distress episodes (cleaning up after the crises occur), but more importantly how to lean against the wind (understand the chain of events leading to external debt crises and try to act in a preventive way). In the empirical literature, two approaches are usually explored.

A first branch of the literature on sovereign debt distress in the emerging economies attempts to identify those factors that are triggers of debt crises and define threshold values on the driving variables that permit early alert of debt stress outcomes. This literature builds upon a signal extraction approach by looking at the behavior of different macroeconomic variables that have been historically associated with debt crises: inflation, trade imbalances, fiscal and monetary policies, financial stress, extreme episodes of capital flows, etc. Debt crises have also often been associated with currency and banking crises. This literature therefore explores the triggers of sovereign debt crises and debt stress episodes using early warning models. The literature is massive and we refer the reader to some seminal papers by Berg and Patillo (1999), Herrera and Garcia (1999), Kamin and Babson (1999), Kaminsky and Reinhart (1999), Ciarlone and Trebeschi (2005) and to recent contributions by Arellano (2008), Boonman et al. (2014), Manasse and Roubini (2009), Savona and Vezzoli (2015).

A second branch of the literature examines over-indebtedness through indicators of debt sustainability. The frequency of situations of debt distress in the emerging countries has been explained by the snowball effect (high interest rates above the economic growth rate), the original sin (countries borrow in foreign currency), currency mismatch (the currency denomination of the countries assets differ from that of their liabilities), the fiscal sin (fiscal policy pro-cyclical bias), the initial stock of debt. Debt sustainability analysis (DSA) has been developed as a way of getting insight into the probability that external debt becomes unsustainable in the face of plausible shocks. Probabilistic frameworks are therefore used to provide estimation of upper and lower intervals of the future evolution of debt. The idea is to assess, 
prospectively, which changes in policies should be undertaken today to prevent the future occurrence of debt crises if adverse shocks were to happen. Here also the literature is massive. For recent contributions, we refer the reader to the papers by Adler and Sosa (2013), Aguiar and Amador (2014), Tanner and Samake (2008).

This paper proposes a new approach of debt distress or debt crises in the emerging economies, based on the study of the distribution of external debts. We investigate debt distress as changes in the ratio of external debt over fiscal revenue that are extreme or large (relative to normal situations), but not rare. A situation of debt distress or debt crisis is defined by the probability that the debt ratio jumps above a given threshold. We consider distributions in the family of the so-called extreme values distribution (GEV) of Jenkinson (1955), with a specific attention to distributions with a decay like a power function rather than those with an exponential rate of decay. The reasons are twofold. First, debt crises in the emerging countries have been found to happen fairly often (they are not rare). Secondly, changes from normal to abnormal debt situations do not necessarily occur abruptly. Indeed, unlike in the developed countries, extreme debt events in the emerging countries are not events occurring only under extraordinary economic events (shocks hitting the economies or the financial systems implying a huge variance in the data that disappear when the shocks are switched off). Conversely, the sources of uncertainty causing changes in the ratio of external debts are endogenous to the economic system, since the factors determining the dynamics of debt in normal time are the same factors triggering debt stress episodes. For both reasons, we need distributions whose tails decay more slowly than those of Weibull or Gumpel distributions. We therefore consider distributions in the basin of attraction of Fréchet distributions. The candidate distributions being potentially large (Pareto, Cauchy, Student-t etc.) we focus on a class of distributions that we motivate theoretically: power-law functions. See Gabaix (2009) for a detailed characterization of power-laws and a survey of empirical power-laws.

After providing empirical evidence that the distributions of their external debt-to-fiscal revenues ratio is represented by a power-law function, we propose a theoretical explanation of the occurrence of such a power-law. More specifically, we develop a continuous time stochastic optimal growth model where the dynamics of debt is described by an Itô diffusion process. The sources of uncertainty are intrinsic to the economic system and come from 
both tax evasion (households only report a fraction of their income to the fiscal administration) and corruption (a fraction of fiscal revenues is stolen by corrupted bureaucrats, see Célimène et al. (2016) for similar assumptions in a closed economy framework). Fraud activity is risky because the households can be caught with a given probability and fined, if this happens. Similarly, the fiscal administration faces a situation of uncertainty because the corrupted bureaucrats are not known with certainty. It only has a suspicion that some of its civil servants are corrupted. We examine the asymptotic behavior of our variables using the concept of steady state in a stochastic sense. The steady state is defined in terms of a probability density function which is shown to be a power-law.

The remainder of the paper is organized as follows. Section 1 establishes empirical evidence that the external debt-to-fiscal revenue ratio has a power-law distribution in the emerging countries. We go beyond the visual inspection of a log-log graph of the distribution of the series, by estimating the scale coefficient and by testing formerly the hypothesis of a power-law distribution. Section 2 contains our theoretical model. Finally, Section 3 concludes.

\section{Empirical power-laws in foreign debt-to-public revenue ratio}

Let us look at the data in Figures 1 to 3. We plot the ratio of external debt over public revenues for some major emerging countries. The data are quarterly from 1980 (1990 for some countries) to 2014 and are taken from Oxford Economics and national sources (central banks and statistical institutes). Foreign debt data do not only comprise the general government's external debt but also include external debt issued by the private sector. Public revenues data correspond to central and local government revenues in local currency, including different types of taxes, interest receipts and dividends from state owned enterprises. To compare them with the ratio of external debt on GDP, these public revenues are then divided by nominal GDP (at market prices, in local currency).

We show the non-parametric distribution of the ratio using both a Gaussian and Epachenikov Kernel. The countries are shared over three regional areas : Latin America, Asia and Europe. We see that many of the distributions have fat tails in their right side and do not seem to fit with a Normal 
law. The probability of finding extreme values for the external debt ratio is higher than for a Gaussian distribution. These extreme values reflect situations of external debt vulnerability, which may cause financial tensions (rising interest rates, currency depreciation, capital outflows). To prevent such situations, policymakers may seek to estimate the probability that the debt ratio exceeds a certain value which is believed to correspond to episodes of debt stress or crises. This is usually done thanks to early warning indicators. A more accurate way to proceed is to estimate a parametric law that approximates the observed distributions. In what follows, we show that the extreme values observed in Figures 1 to 3 follow power-law distributions, more specifically Pareto type 1 distributions.

Formally, a continuous variable $x$ obeys a power-law with parameter $\alpha$ if its probability density function is written as

$$
p(x)=\left\{\begin{array}{ll}
C x^{-\alpha}, & x \geq x_{\min } \\
0, & x<x_{\min }
\end{array},\right.
$$

with the normalizing constant $C=\frac{\alpha-1}{\left(x_{\min }\right)^{-\alpha+1}}, x_{\text {min }}$ being the lower bound of the power-law behavior and $\alpha$ the scaling parameter.

The $m$-th order moment is given by

$\left\langle x^{m}\right\rangle=\int_{x_{\text {min }}}^{\infty} x^{m} p(x) d x=\frac{\alpha-1}{\alpha-1-m} x_{m i n}^{m}$, which is well defined for $m<\alpha-1$.

For finite size samples, the central moments like the mean and the variance are not finite. Typical values for Pareto laws in economics are found for $\alpha$ in the interval $(2,3)$ for which the mean is well defined and exists but the variance and higher-order moments are infinite.

\subsection{Estimates of power-law based on bootstrap methods}

We first estimate the lower bound $x_{\text {min }}$ from which the data can be considered to follow a power-law. We follow Clauset et al. (2009). For a given $x_{\text {min }}$ (assumed to be known), we compute the maximum likelihood estimator of $\alpha$ :

$$
\hat{\alpha}=1+n\left[\sum_{i=1}^{n} \ln \left(\frac{x_{i}}{x_{\min }}\right)\right]^{-1}
$$




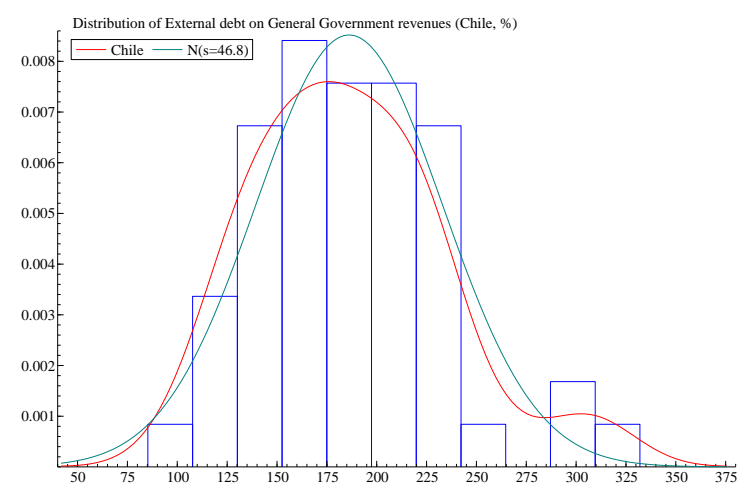

1. Chile

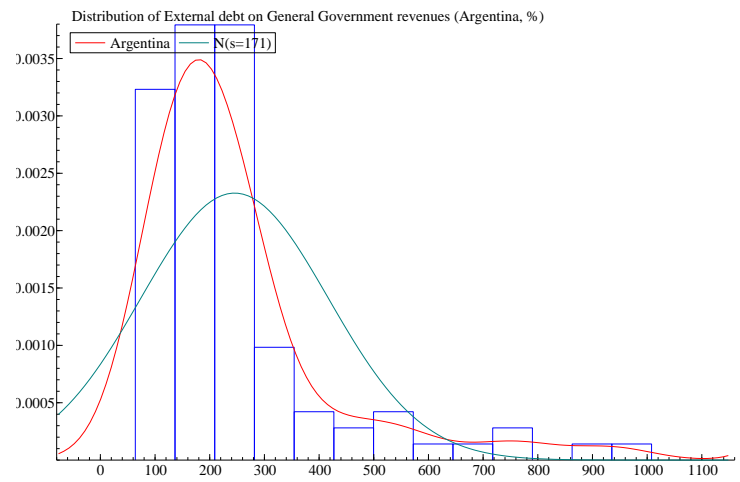

3. Argentina

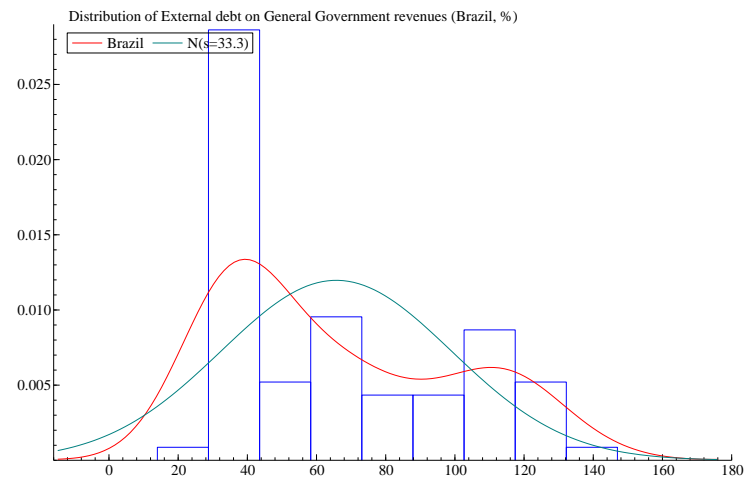

5. Brazil

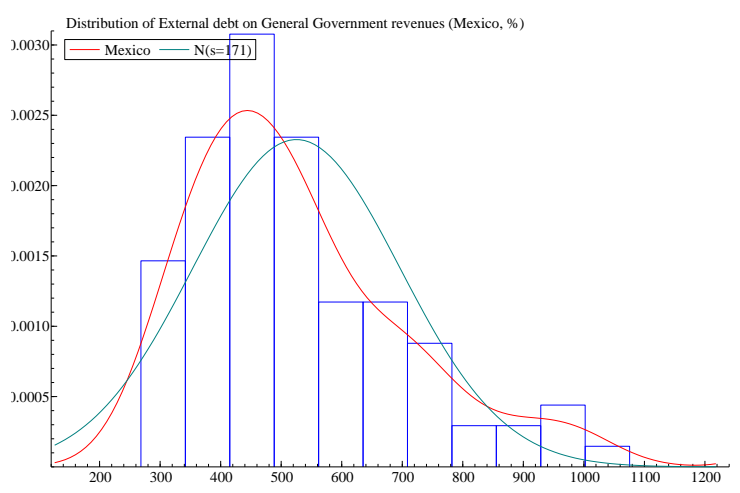

2. Mexico

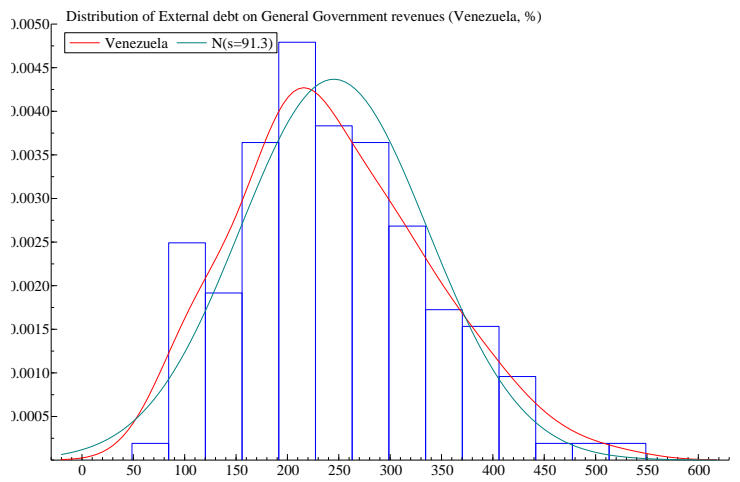

4. Venezuela

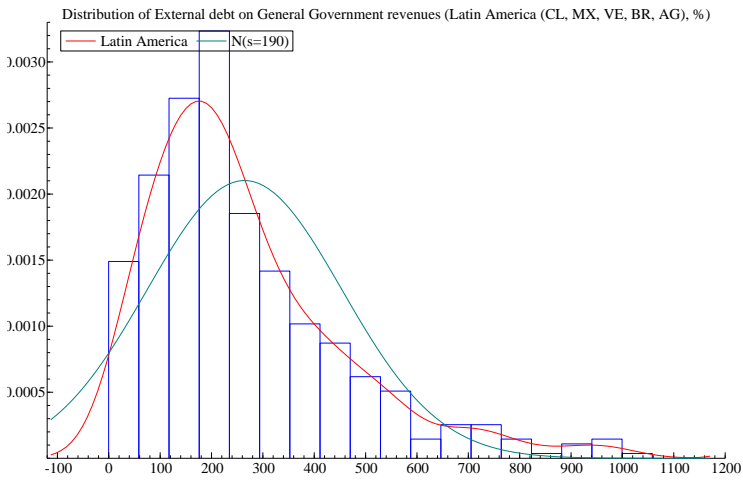

6. Latin America

Figure 1: Distribution of External debt as share of public revenues (\%), Latin America 


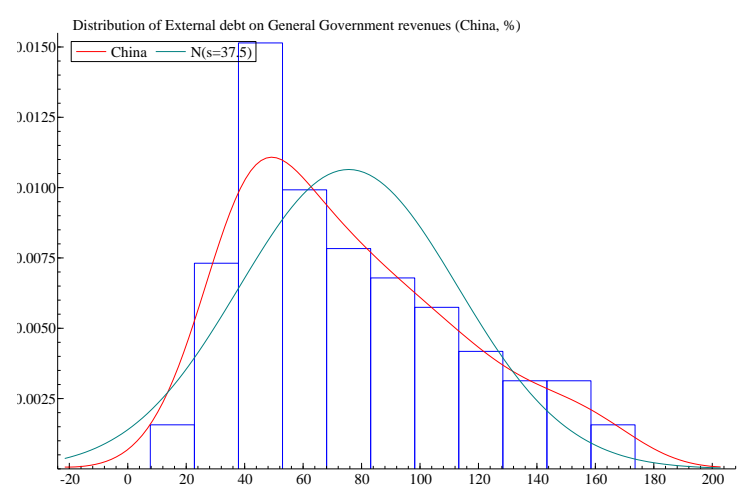

1. China

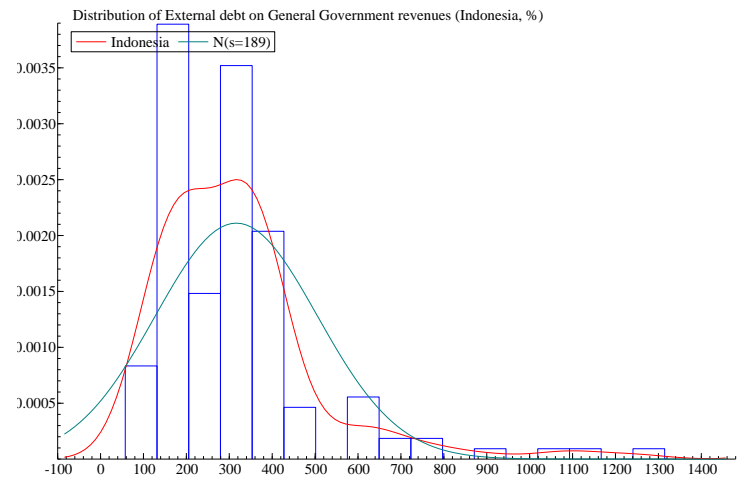

3. Indonesia

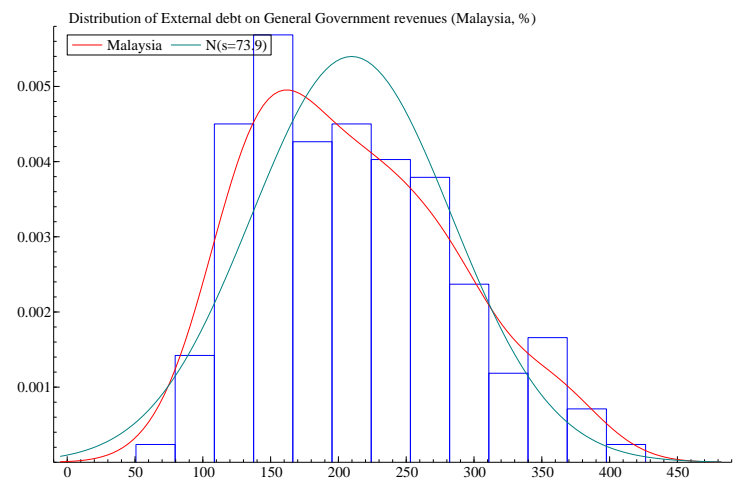

5. Malaysia

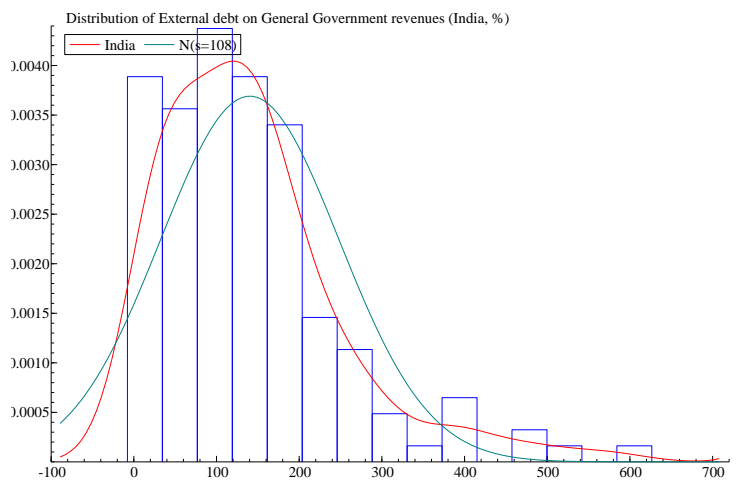

2. India

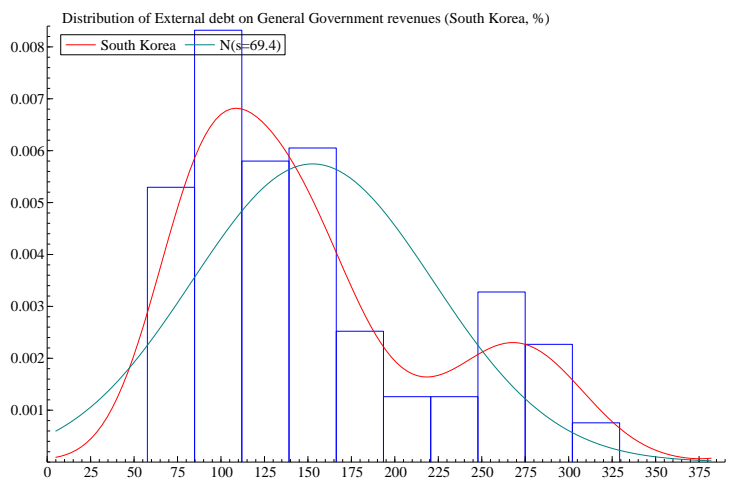

4. South Korea

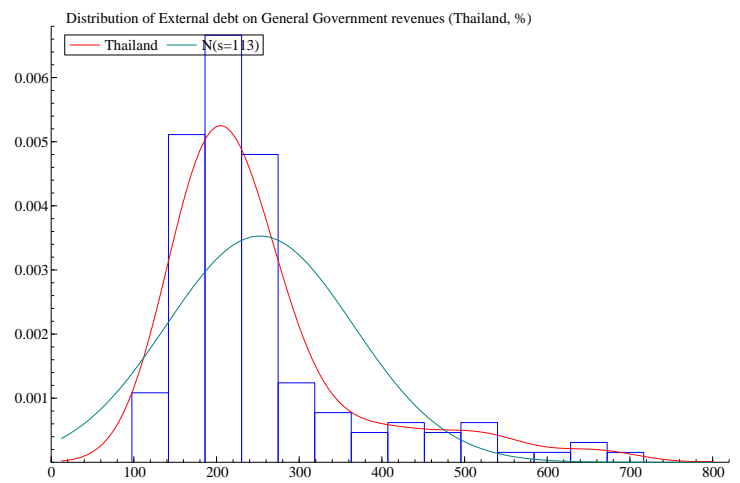

6.Thailand

Figure 2: Distribution of External debt as share of public revenues (\%), Asia 


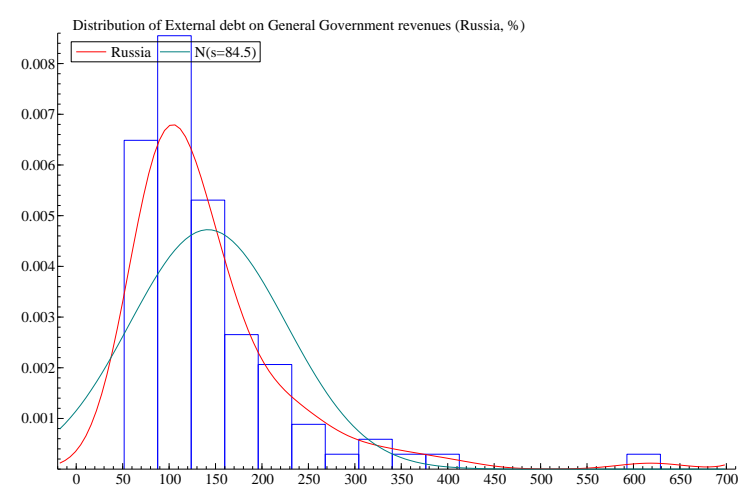

1. Russia

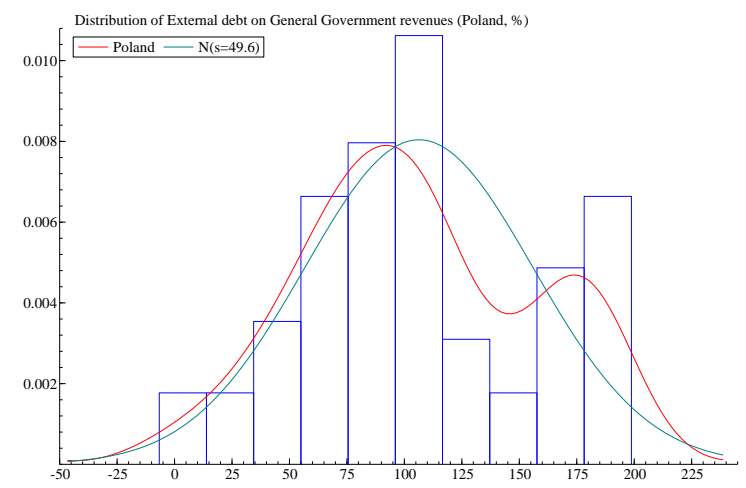

3. Poland

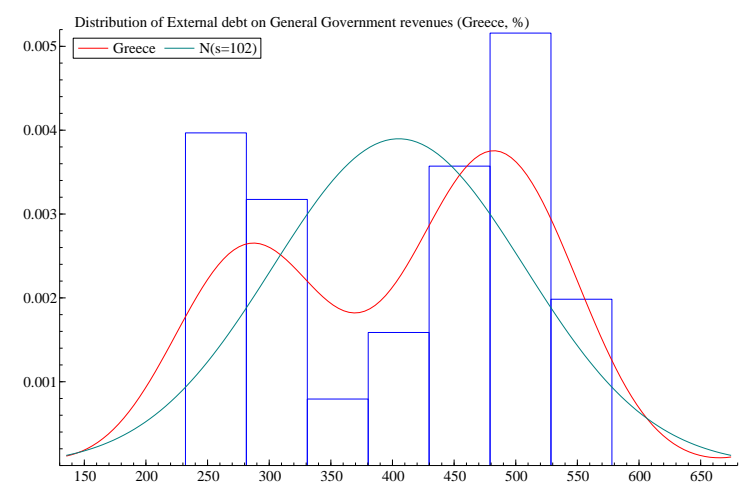

5. Greece

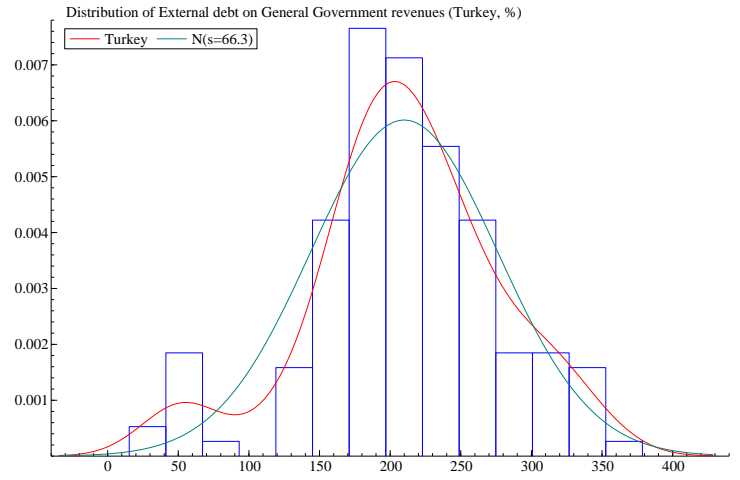

2. Turkey

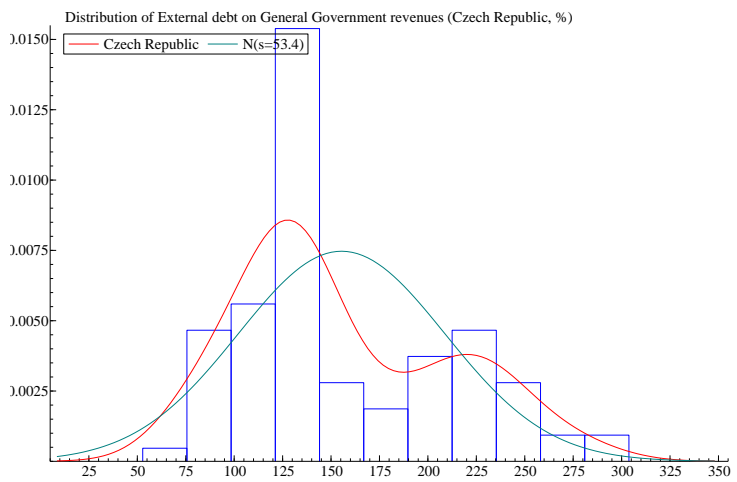

4.Czech Republic

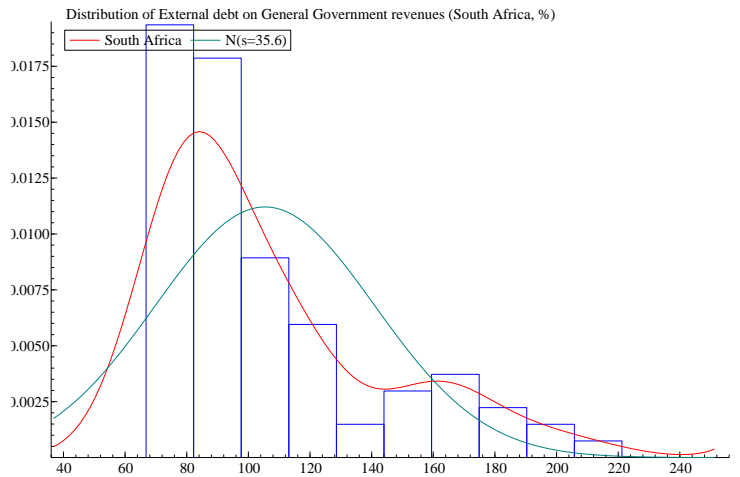

6.South Africa

Figure 3: Distribution of External debt as share of public revenues (\%), Europe, Russia and South Africa 
whose standard error is equal to $\frac{\hat{\alpha}-1}{\sqrt{n}}+O(1 / n)$, with $\mathrm{n}$ being the number of observed values being higher than $x_{\text {min }}$. $\hat{\alpha}$ corresponds to the shape parameter of the best fitting power-law, for this given value of $x_{\min }$. Then, we compute the weighted Kolmogorov-Smirnov statistic, defined as the distance between the CDFs of the empirical data and the best fitting power-law model:

$$
D^{*}\left(x_{\text {min }}\right)=\max _{x \geq x_{\text {min }}} \frac{|S(x)-P(x)|}{\sqrt{P(x)(1-P(x))}},
$$

where $S(x)$ is the CDF of the data for the values higher than $x_{m i n}$, and $P(x)$ is the CDF of the power-law model that best fits the data for $x \geq x_{\text {min }}$. Using a scale of possible values for $x_{\text {min }}$, the "optimal" $x_{\text {min }}$ is finally computed so as to make the distributions of the empirical data and of the best fitting power-law as close as possible:

$$
\hat{x}_{\text {min }}=\underset{x_{\text {min }}}{\operatorname{argmin}} D^{*}\left(x_{\min }\right) .
$$

It minimizes $D^{*}$ on a range of possible values for $x_{m i n}$. The mean and standard errors of the estimated parameters $\hat{x}_{\min }$ and $\hat{\alpha}\left(\hat{x}_{\min }\right)$ are then obtained by a bootstrap procedure. This consists in drawing $\mathrm{N}$ draws $(\mathrm{N}=1000)$ uniformly at random from the original dataset, estimating $\alpha$ and $x_{\min }$ again for each of these series.

\subsection{Regression-based approaches}

The previous method is based on the assumption that a power-law can fit the data well, which is not necessarily true. To evaluate whether a Pareto law really fits the data, we proceed by using a rank-regression approach proposed by Gabaix and Ibragimov (2011).

By OLS, we run the log-log rank-size regression (for $\gamma=0.5$ ):

$$
\log (t-\gamma)=a-b \log (Z(t)) \Leftrightarrow \log (\operatorname{Rank}-\gamma)=a-b \log (\text { Size }),
$$

where $t$ is the rank of the observations Z(t) (ranked in decreasing order). The standard error of the shape coefficient $b$ id $\sqrt{\frac{2}{n}} \hat{b}$, with $n$ the "total" rank, i.e. the number of observations higher than $x_{\min }$ (i.e. following a power-law). 
Another way to compute this standard error is to estimate the opposite regression:

$$
\log (Z(t))=a_{2}-b_{2} \log (t-\gamma),
$$

where the shape coefficient is obtained by $\frac{1}{\hat{b_{2}}}$ whose standard error is $\sqrt{\frac{2}{n}} \frac{1}{\hat{b_{2}}}$. One can plot $\log (t-0.5)$ against $\log (Z(t))$, as well as the straight line whose equation we have estimated, such that we see if the data fits well with the power-law on this log-log plot. Gabaix and Ibragimov (2011) show that the bias is optimally reduced for $\gamma=0.5$.

\subsection{Evidence of Pareto laws in foreign debt data}

Tables 1 and 2 show the estimates for our sample of countries. Graphs of log-log plots of the estimates are not reported to save place but are available upon request to authors. The estimates suggest that many of the distributions of the ratio of the external debt over public revenues can be approximated by power-laws. The scale exponent lies between 2 and 4 which are typical values for which power-law behaviors are usually observed. This has several implications for the analysis of the emerging countries' external debt.

Firstly, the standard analysis of debt sustainability, that consists of examining how some economic shocks can make the debt ratio deviate from their "normal" levels, can be misleading. Indeed, with power-laws, each new event changes the central and higher moments of the distribution, so that debt does not necessarily stabilize around an equilibrium value. It seems more appropriate to focus on finding critical levels around which the debt oscillates and from which debt crises can occur.

Secondly, in power-law distributions, extreme events are not rare. This accords with the finding that some emerging countries have been found to be "serial defaulters" on their foreign debt : if they have defaulted in the past, they are very likely to default again in the future (the literature on serial sovereign default is abundant). For a recent literature review, see Asonuma (2016).

\section{Tax evasion and corruption as causes of power-laws in foreign debt ratios: a theoretical model}

What causes high external debt in the emerging countries? The literature suggests that episodes of foreign debt distress have been systematically as- 


\begin{tabular}{lcccc} 
& $x_{\min }$ & s.e. (bootstrap) & $\alpha$ & s.e. (bootstrap) \\
\hline Chile & 132,3 & 19,9 & 3,99 & 1,52 \\
Mexico & 336,7 & 45,7 & 3,48 & 0,63 \\
Argentina & 111,1 & 48,02 & 2,52 & 0,41 \\
Venezuela & 135,6 & 45,7 & 2,92 & 0,80 \\
Brazil & 31,2 & 12,3 & 2,43 & 0,42 \\
China & 34,2 & 17,7 & 2,32 & 0,45 \\
India & 20,04 & 17,62 & 1,59 & 0,07 \\
Indonesia & 114,4 & 43,1 & 2,09 & 0,19 \\
South Korea & 78,5 & 11,9 & 2,75 & 0,29 \\
Malaysia & 119,4 & 18,04 & 3,05 & 0,50 \\
Thailand & 157,2 & 17,4 & 3,56 & 0,47 \\
Russia & 73,8 & 17,4 & 2,82 & 0,38 \\
Turkey & 122,4 & 43,4 & 3,49 & 1,34 \\
Poland & 51,4 & 33,9 & 2,49 & 0,89 \\
Czech Republic & 103,6 & 20,7 & 3,68 & 0,79 \\
Greece & 260,5 & 63,4 & 2,81 & 1,49 \\
South Africa & 71,7 & 7,1 & 3,98 & 0,61 \\
\hline
\end{tabular}

Table 1: Estimated lower bound $x_{\min }$ and associated $\alpha$ (bootstrap) 


\begin{tabular}{lcccc} 
& b (Reg 1) & standard error & $1 / \mathrm{b}($ Reg 2) & standard error \\
\hline Chile & 4,16 & 0,85 & 4,79 & 0,98 \\
Mexico & 3,33 & 0,51 & 3,7 & 0,57 \\
Argentina & 1,92 & 0,29 & 2,03 & 0,31 \\
Venezuela & 2,95 & 0,37 & 3,55 & 0,44 \\
Brazil & 1,81 & 0,31 & 2,37 & 0,40 \\
China & 1,97 & 0,26 & 2,43 & 0,32 \\
India & 1,04 & 0,12 & 1,43 & 0,17 \\
Indonesia & 1,84 & 0,22 & 2,14 & 0,25 \\
South Korea & 2,21 & 0,27 & 2,67 & 0,33 \\
Malaysia & 2,87 & 0,35 & 3,55 & 0,44 \\
Thailand & 2,77 & 0,34 & 2,89 & 0,35 \\
Russia & 2,22 & 0,34 & 2,28 & 0,35 \\
Turkey & 3,87 & 0,47 & 4,74 & 0,58 \\
Poland & 2,33 & 0,34 & 3,2 & 0,46 \\
Czech Republic & 3,18 & 0,50 & 3,8 & 0,60 \\
Greece & 3,13 & 0,65 & 5,32 & 1,11 \\
South Africa & 3,19 & 0,50 & 3,48 & 0,55 \\
\hline
\end{tabular}

Table 2: Estimated $\alpha$ using rank-1/2 regression 
sociated with other macroeconomic and financial imbalances, among which hyper-inflation, banking crises, asset price bubbles, credit booms, capital flows, the cyclical nature of fiscal and monetary policies. See Kaminsky et al. (2005), Reinhart and Rogoff (2008), Reinhart and Rogoff (2011), Reinhart and Rogoff (2013).

What is distinctive in our paper relative to previous works is that we explain theoretically how outcomes of high external debt ratio depicted by a power-law distribution can arise from loose civic capital or governance, captured by tax evasion and bureaucratic corruption in the fiscal administration. Both these factors weaken a country's fiscal position by contracting government's revenues. Public spending is therefore financed through a forcible foreign borrowing. Since tax revenues account for the greatest part of public revenues and given that interest receipts and dividends from state owned enterprises are exogenous (in the sense that they do not directly depend upon tax evasion and corruption behaviors), we focus on tax revenues as the denominator of the external debt ratio. We propose a simple continuous time stochastic growth model from which the exact asymptotic distribution of foreign debt-to-fiscal revenue ratio is obtained using results from the theory of stochastic differential equations.

Two types of uncertainties are introduced into the model. First, we consider lotteries on tax evasion and corruption behaviors which give us the expected return to cheating for both households and bureaucrats, given the risks of being a fraudulent and a corrupt government. Secondly, we consider diffusion processes as follows.

Consider a random variable $X(t)$. Its change between time $t$ and $t+d t$ is defined by the Itô stochastic differential equation:

$$
d X(t)=f(X(t)) d t+g(X(t)) d Z .
$$

$f$ and $g$ are two continuous functions and $Z$ is a Brownian motion : $d Z \approx$ $N(0, d t)$ and $d t$ is of infinitesimal order. Moreover, we assume that $Z$ is a Markovian process in the sense that $d Z$ depends neither on $t$ nor on its

past values. This assumption will allow us to use the general properties of diffusion processes to derive a probability distribution for our main variable of interest.

\subsection{Production}

We consider an open economy specialized in the production of a single good. This good is the numeraire and its price is normalized to 1 . The 
country comprises $\mathrm{N}$ inhabitants (consumer/taxpayers and workers). All the variables in the model are expressed in per-capita terms. The individuals differ in their behaviors as taxpaypers (some are fraudulent, others are not), but their consumption and production decisions are the same.

The single domestic good of the economy is produced with capital, labor (fixed amount) and public spending

$$
y(t)=k(t)^{\beta} g(t)^{1-\beta},
$$

where $y(t)$ is per-capita income, $k(t)$ is private capital-labor ratio, $g(t)$ is percapita productive public spending (infrastructure, public goods and services). We assume constant returns to scale $(0<\beta<1)$.

Domestic capital yields a stochastic return. The flow of private rate of return on capital over the period $(t, t+d t)$ is subject to a stochastic disturbance:

$$
d R_{k}(t)=r_{k} d t+d u_{k}
$$

where the drift component $r_{k}=\frac{\partial F}{\partial k}$ is a constant return to private capital and the diffusion component $d u_{k}$ is a Brownian motion.

\subsection{Tax evasion}

A consumer is faced with the decision of whether or not to hide a share of his actual income $y(t)$ to evade taxes. The income tax rate $\tau$ is constant. He hides a fraction $e(t)$ of the income $(0<e(t)<1)$. Therefore $[1-e(t)] y(t)$ is the amount of reported income. The probability of being detected as a fraudulent by the administration is $p(0<p<1)$ and, if caught, the taxpayer pays the due tax plus a penalty. $b$ is the penalty rate on the amount of evaded tax $b \tau e(t) y(t)$. Therefore, the consumer pays $\tau[1-e(t)] y(t)$ if he is not detected and $\tau y(t)+b e(t) y(t)$ if he is caught. The return of each unit of evaded tax is described by the following lottery:

$$
x= \begin{cases}1, & \text { w.p. } 1-p \\ -b, & \text { w.p. } p\end{cases}
$$

The expected gain and risk of the lottery are defined by

$$
\bar{x}=(1-p)-p b, \sigma^{2}=\mathbb{E}\left(x^{2}\right)-\mathbb{E}(x)^{2}=\mathbb{E}\left(x^{2}\right)-\bar{x}^{2} .
$$

$\bar{x}$ and $\sigma^{2}$ are function of $p$ and $b$. 


\subsection{Corruption and government's choice}

The tax administration consists of bureaucrats whose number is the same as the consumer ${ }^{3}$. A fraction $p_{1}$ of them are corrupted and a fraction $1-p_{1}$ who are non-corrupted $\left(0<p_{1}<1\right)$. Bureaucratic corruption arises when civil servants charged with the responsibility for collecting taxes choose to extort a fraction $\theta(t)$ of tax revenues (it happens with a probability $p_{1}$ ). They steal a fraction of tax resources which normally serves to finance public goods that enter as inputs in the production activity.

A fraction $p_{1} \theta(t)$ of tax revenues is stolen and converted to unproductive public spending (or public consumption). Per-capita public spending is therefore described by

$$
g(t)= \begin{cases}\left(1-p_{1} \theta(t)\right)[\tau y(t)+b e(t) y(t)], & \text { w.p. } p \\ \left(1-p_{1} \theta(t)\right) \tau(1-e(t)) y(t), & \text { w.p. }(1-p)\end{cases}
$$

and the dynamics of productive public spending is given by the following stochastic differential equation (SDE):

$$
d g(t)=\bar{g}(t) d t+\tilde{g}(t) d W^{g},
$$

where $W^{g}$ is a Brownian motion, $\bar{g}(t)$ is the expected productive public expenditure from the above lottery and $\tilde{g}^{2}(t)=\mathbb{V}(g(t))=\mathbb{E}\left(g(t)^{2}\right)-\mathbb{E}(g(t))^{2}$ is the variance of the lottery. Unproductive public spending (the share of diverted tax revenues which we consider to be public consumption) is given by

$$
C^{G}(t)=\left\{\begin{array}{ll}
0, & \text { w.p. }\left(1-p_{1}\right) \\
\theta(t)[\tau y(t)+b e(t) y(t)], & \text { w.p. } p p_{1} \\
\theta(t) \tau(1-e(t)) y(t), & \text { w.p. } p_{1}(1-p)
\end{array} .\right.
$$

The dynamics of public consumption is described by the following SDE

$$
d C^{G}(t)=\bar{C}^{G}(t) d t+\tilde{C}^{G}(t) d W^{C^{G}}
$$

where $W^{C^{G}}(t)$ is a Brownian motion and

$$
\bar{C}^{G}(t)=\mathbb{E}\left(C^{G}(t)\right)=p_{1} \theta(t) y(t)[p b e(t)+p \tau e(t)+\tau(1-e(t))],
$$

\footnotetext{
${ }^{3}$ The assumption that the number of bureaucrats equals those of consumers is made for technical simplicity and does not change our arguments.
} 


$$
\tilde{C}^{2}=\mathbb{V}\left(C^{G}(t)\right)=\mathbb{E}\left(C^{G}(t)^{2}\right)-\mathbb{E}\left(C^{G}(t)\right)^{2}=\mathbb{E}\left(C^{G}(t)^{2}\right)-\overline{C^{G}}(t)^{2} .
$$

In this stochastic framework, the balanced budget constraint describes how the flow of tax revenues is assigned to the flows of productive and unproductive public spending:

$$
d T(t)=\left[\bar{g}(t)+\bar{C}^{G}(t)\right] d t+\tilde{g} d W^{g}(t)+\tilde{C^{G}} d W^{C^{G}},
$$

where

$$
\bar{C}^{G}(t)=p_{1} \theta(t) y(t)[p b e(t)+p \tau e(t)+\tau(1-e(t))]
$$

$p_{1} \theta(t)$ can be interpreted as a corruption index ranging from 0 (low corruption) to 1 (high corruption). It depends upon the proportion of corrupted bureaucrats and the degree of prevarication in the use of public resources. We assume that the bureaucrats' punishment for being corrupt is nil. This is a distinguishing feature of countries with poor governance (lack of transparency and accountability, inefficient court systems). Moreover, it is assumed that $\theta(t)>0$ in the sense that corruption is a rent seeking activity that is privately beneficial, and that $\theta(t)<1$, because corruption inhibits growth (by reducing the productivity of private capital) and therefore reduces the amount of the rent. Therefore, the bureaucrats' aim is to define an optimal degree of prevarication (how much to steal) that maximizes public consumption.

The government maximizes its intertemporal expected utility function defined on public consumption subject to the constraint (19):

$$
\max _{n^{G}, n^{C}} \mathbb{E} \int_{0}^{+\infty} \frac{1}{\gamma}\left(T(t) n_{C}(t)\right)^{\gamma} e^{-\rho t} d t, \rho>0,-\infty<\gamma<1,
$$

subject to

$$
\frac{d T(t)}{T(t)}=\psi^{T}(t) d t+\sigma_{w^{T}}(t) d w^{T}, T \in(0, \infty)
$$

and

$$
n_{g}(t)+n_{C}(t)=1
$$

where

$$
\begin{gathered}
n_{g}(t)=\frac{\bar{g}(t)}{T(t)}, n_{C}(t)=\frac{\bar{C}^{G}(t)}{T(t)}, \psi^{T}(t)=\frac{\bar{g}(t)}{T(t)}+\frac{\bar{C}^{G}(t)}{T(t)}, \\
\sigma_{w^{T}}^{2}(t)=\tilde{n}_{g}(t)^{2} \sigma_{W^{g}}^{2}(t)+\tilde{n}_{C}^{2}(t) \sigma_{W^{C} G}^{2}(t)
\end{gathered}
$$




$$
\tilde{n}_{g}(t)=\frac{\tilde{g}(t)}{T(t)}, \tilde{n}_{C}(t)=\frac{\tilde{C}^{G}(t)}{T(t)} .
$$

The solution to the maximization problem of the government gives an optimal path of the share of public consumption out of total fiscal revenues defined by (we omit the index $t$ for purpose of simplification) ${ }^{4}$

$$
\hat{n_{C}}=\frac{\sigma_{W^{g}}^{2}+\sqrt{\sigma_{W^{g}}^{4}-4\left(\sigma_{W^{C}}^{2}+\sigma_{W^{g}}^{2}\right)\left(\frac{\rho-\gamma}{1-\gamma}+\frac{1}{2} \sigma_{w^{T}}^{2} \gamma\right)}}{2\left(\sigma_{W^{C}}^{2}+\sigma_{W^{g}}^{2}\right)}
$$

This solution illustrates the role of the relative aversion risk coefficient (1$\gamma)$. When corruption takes place, there is a chance that lean times could occur in the future. A bureaucrat could suffer from loss in his future consumption because the outcome of diverting tax revenues is lower productive public spending, lower production and thus lower tax base.

\subsection{The open economy and external debt}

Insofar as tax evasion and corruption do not allow the domestic country to produce the amount of the single domestic good that households would like to consume ${ }^{5}$, the country needs to buy a foreign good from abroad. We adopt the convention that imports of goods is equivalent to external borrowing, so that external debt is defined as the domestic country's net international current account position (i.e. $C(t)^{M}=D(t)$ ). We make the following assumptions:

- $P^{M}$ is the price of imports and therefore $1 / P^{M}$ is a proxy of the terms of trade. Import price changes are described by the following SDE:

$$
\frac{d P^{M}(t)}{P^{M}(t)}=\pi d t+d P
$$

where $\pi$ defines changes in the terms of trade and $P$ is a Brownian motion.

\footnotetext{
${ }^{4}$ See Appendices A and C.

${ }^{5}$ Tax evasion constrains funding of total public spending and corruption erodes its productive share, as corrupted public consumption is unproductive.
} 
- Debt is denominated in terms of the foreign output and its price is expressed in terms of the price of the numeraire $P^{M} D$. The interest rate paid on foreign debt is stochastic and described by

$$
d R_{f}(t)=r_{f} d t+d u_{f}, r_{f}=i^{*}+\pi \text { and } d u_{f}=d P .
$$

where $r_{f}$ is the real world interest rate assumed to be constant.

\subsection{Consumer's choice}

The domestic country comprises agents who consume the domestic and the imported goods. The agent bears domestic assets (he owns the firm) and foreign liabilities (he pays back the foreign debt). His wealth constraint is given by

$$
W(t)=K(t)-P^{M}(t) D(t), W \in(0, \infty) .
$$

This implies

$$
\frac{K(t)}{W(t)}-\frac{P^{M}(t) D(t)}{W(t)}=n_{K}(t)-n_{f}(t)=1,
$$

where $n_{K}(t)$ and $n_{f}(t)$ are the shares of capital and foreign debt in total wealth with $0<n_{K}(t)<1$ and $n_{f}(t)>0$ (domestic country assumed to be indebted vis-à-vis the rest of the world).

The stochastic wealth accumulation equation is given by

$$
\begin{aligned}
d W(t)= & {[1-\tau+\bar{x} \tau e(t)] k(t)^{\beta} g(t)^{1-\beta} d t } \\
& -\left(C^{P}(t)+P^{M}\left(t C^{M}(t)\right) d t\right. \\
& +\sigma\left[\tau e(t) k(t)^{\beta} g(t)^{1-\beta}\right] d W^{W} \\
& +k(t) d R_{k}(t)-P^{M}(t) D(t) d R_{f}(t)
\end{aligned}
$$

This equation has several drift and diffusion components:

- Line 1 describes the drift component of the disposable income. The household can inflate his disposable thanks to tax evasion activity. Given (9), we have $(1-\tau) k(t)^{\beta} g(t)^{1-\beta}=(1-\tau) y(t)$. This is the disposable income when there is no tax evasion. $e(t) \tau(t) y(t)$ is the amount of tax evaded. Since tax evasion is a risky activity, we need to consider the expected return of tax evasion that is $\bar{x} e(t) \tau y(t)$ where $\bar{x}$ is defined by (12). 
- Line 2 defines the drift component of consumption, that is the household's consumption of domestic and foreign goods that are assumed to proceed at non-stochastic rates over the interval $(t, t+d t)$.

- Line 3 corresponds to the diffusion component of disposable income or the risk associated to fiscal evasion. The standard error of the Brownian motion $W^{W}$ is $\sigma \tau e(t) y(t)$ where $\sigma$ is defined by (12).

- Line 4 (first expression) $k(t) d R_{k}(t)$ describes both the deterministic and the stochastic shocks to the productivity of private capital.

- Line 4 (second expression) $P^{M}(t) D(t) d R_{f}(t)$ describes the influence of the international financial markets and of the terms of trade shocks which impact the interest rate paid on external debt.

The consumer's objective is to choose his domestic and foreign consumption, the amount of income to hide and his portfolio of net assets (assets minus liabilities) in order to maximize the expected value of discounted utility subject to the constraint given by (C.2):

$$
\max _{C^{P}, C^{M}, e, n_{K}, n_{f}}=\mathbb{E} \int_{0}^{+\infty} \frac{1}{\mu}\left[C^{P}(t)^{\eta} C^{M}(t)^{1-\eta}\right]^{\mu} e^{-\rho t} d t, \rho>0,-<\mu<1,
$$

subject to

$$
\frac{d W(t)}{W(t)}=\psi^{W}(t) d t+\sigma_{z^{W}}(t) d z^{W}, n_{K}(t)-n_{f}(t)=1,
$$

and $W(0)=w_{0}$, where

$$
\begin{gathered}
\psi^{W}(t)=\left[\begin{array}{l}
{[1-\tau+\bar{x} \tau e(t)] n_{k}^{\beta}(t) n_{g}^{1-\beta}(t)\left(\frac{T(t)}{W(t)}\right)^{1-\beta}-\frac{C P I(t) C(t)}{W}+} \\
\quad n_{k}(t) r_{k}-\left(i^{*}+\pi\right) n_{f}(t),
\end{array}\right. \\
\sigma_{z^{W}} d z^{W}=\sigma \tau e(t) n_{k}^{\beta}(t) n_{g}^{1-\beta}(t)\left(\frac{T(t)}{W(t)}\right)^{1-\beta} d W^{W}+n_{k}(t) d u_{k}-n_{f}(t) d u_{f} . \quad(36) \\
n_{k}(t)=\frac{k(t)}{W(t)} \text { and } n_{f}(t)=\frac{P(t)^{M} D(t)}{W(t)} \text { are respectively the share of capital }
\end{gathered}
$$
and foreign debt in total wealth ${ }^{6}$.

\footnotetext{
${ }^{6}$ Assuming the same rate of time preference for the government and the household is made for simplicity and does not have any consequence on our results.
} 
The optimal path is described by the following system of recursive equations $^{7}$ :

$$
\left\{\begin{array}{l}
\hat{C}(t)=(\delta \mu)^{\frac{1}{\mu-1}}\left(P^{M}(t)\right)^{\frac{1-\eta}{\mu-1}} W(t) \\
\hat{e}(t)=\frac{\bar{x} \tau \hat{n_{k}}(t)^{\beta} n_{g}(t)^{1-\beta}\left(\frac{T(t)}{W(t)}\right)^{1-\beta}}{(1-\mu)\left[\sigma \tau \hat{n_{k}}(t)^{\beta} n_{g}(t)^{1-\beta}\left(\frac{T(t)}{W(t)}\right)^{1-\beta} \sigma_{W W}(t)\right]^{2}} \\
\hat{n}_{k}(t)=\frac{r_{k}-\left(i^{*}+\pi\right)+(1-\mu) \sigma_{W^{f}}(t)^{2}+\sqrt{\triangle}}{2(1-\mu)\left(\sigma_{W^{k}}(t)^{2}+\sigma_{W^{f}}(t)^{2}\right)} \\
\hat{n}_{f}(t)=\hat{n}_{k}(t)-1
\end{array}\right.
$$

with $\triangle=\left[r_{k}-i^{*}-\pi+(1-\mu) \sigma_{W^{f}}^{2}\right]^{2}$

$-4(1-\mu)\left(\sigma_{W^{k}}^{2}+\sigma_{W^{f}}^{2}\right)\left[(1-\mu) \beta \sigma^{2} \tau^{2} \hat{e}^{2} \sigma_{W^{W}}^{2} n_{y}^{2}-\beta[1-\tau+\bar{x} \tau \hat{e}] n_{y}\right]$.

From the first equation, we see that total private consumption (private domestic goods plus imports) increases with wealth. Moreover, an increase in import prices (deterioration of the terms of trade) raises the nominal debt and accordingly reduces the nominal net wealth (since $W(t)=K(t)-$ $\left.P^{M}(t) D(t)\right)$. In this case the households reduces his consumption (balance sheet effect).

From the second equation of the system, it is seen that the incentive for tax avoidance increases when the return on each unit of hidden income increases relative to the risk of being caught $(\hat{e}(t)$ is an increasing function of $\left.\bar{x} / \sigma^{2}\right)$. Consumers are also prone to cheat more if their relative risk aversion $1-\mu$ decreases. Moreover the taxpayer is more likely to cheat when production over total wealth $n_{y}=n_{g}^{1-\beta} n_{k}^{\beta}\left(\frac{T}{W}\right)^{1-\beta}$ decreases. This happens, either: i) when private capital decreases (the households hold less assets in their portfolio); ii) when corruption by bureaucrats increases (in this case $n_{g}$ diminishes or, equivalently, $n_{c}$ increases); iii) when $T / W$ decreases (as it measures the implicit corruption and fraud tax on the household's net wealth). Indeed, these illegal activities imply that the consumer must borrow from abroad (in the form of imports) and therefore bears the costs of the interest rate charged on external debt. This cost is internalized by the consumer and has an inhibiting effect on tax fraud (we see that $\hat{e}$ is a decreasing function of the ratio $T / W)$.

\footnotetext{
${ }^{7}$ See Appendices B and C.
} 
From the third equation, we see that the capital share in total wealth depends upon the following factors:

- $r_{k}-\left(i^{*}+\pi\right)$ is the expected net rate of return of capital (the capital owned as share of the domestic firm minus the capital borrowed from abroad). It is inversely proportional to the risks of both types of capital $\left(\sigma_{W^{k}}(t)^{2}+\sigma_{W^{f}}(t)^{2}\right)$ and to risk aversion.

- the ratio $\sigma_{W^{f}}(t)^{2} /\left(\sigma_{W^{k}}(t)^{2}+\sigma_{W^{f}}(t)^{2}\right)$ captures the household's dehedging behavior. When the risk of debt holding increases, the households want to own more domestic capital (which is possible by reducing tax evasion).

- We have an additional term $\Delta^{1 / 2}$ that depends on $\hat{e}, W / T, \hat{n}_{c}$.

\section{Power-law as steady state distribution for the external debt ratio}

From Equation (30), the ratio of nominal external debt over nominal fiscal revenues can be defined by

$$
\frac{P^{M}(t) D(t)}{T(t)}=\frac{K(t)}{T(t)}-\frac{W(t)}{T(t)} .
$$

For a given value of the capital/tax income, changes in the external debt/tax revenues ratio are negatively correlated to those in $W(t) / T(t)$. Given the invariance properties of power-law distributions, for a given value of the ratio $K(t) / T(t)$, the existence of a Pareto law for $W(t) / T(t)$ implies that the external debt ratio will also follow a Pareto law. Thus, we define the macroeconomic equilibrium in terms of the ratio of net wealth-to-tax revenues.

A power-law probability density function is derived by proceeding in several steps. First, we specify the dynamics of the ratio $W(t) / T(t)$ by using the Itô's lemma. We thus obtain a Itô stochastic differential equation formulation. Then, a theorem of the existence of a stochastic steady state is proved by using some properties of Markov chain diffusion processes. After that, we show that the stochastic steady state can be defined by a power-law with shape parameter depending upon our key variables of interest in the model related to tax evasion and corruption. Finally, we propose some simulations of the model. 


\subsection{Macroeconomic equilibrium as a diffusion process}

Definition 4.1. Stochastic macroeconomic equilibrium

A stochastic macroeconomic equilibrium is defined as a path of wealthto-fiscal revenues ratio $\{\lambda(t)\}$, where

$$
\lambda(t)=\left\{\frac{W(t)}{T(t)}\right\}_{t=0}^{\infty},
$$

along which the agents' choice (bureaucrats and households) are optimal and the current account is balanced (imports are financed by foreign borrowing).

Theorem 4.1. The stochastic dynamics for the wealth-fiscal revenue ratio is a diffusion process defined by the stochastic differential equation (SDE)

$$
d \lambda(t)=\Omega_{1}(\lambda) d t+\Omega_{2}^{\frac{1}{2}}(\lambda) d B, \quad \lambda(t)=\frac{W(t)}{T(t)} \in[0, \infty],
$$

where

$$
\begin{gathered}
\Omega_{1}(\lambda)=\lambda\left[\tilde{n}_{g}^{2}(\lambda)+\tilde{n}_{C}^{2}(\lambda)-\hat{n}_{g}(\lambda)-\hat{n}_{C}(\lambda)+\right. \\
\left.[1-\tau+\bar{x} \tau \hat{e}(\lambda)] \hat{n}_{y}(\lambda)-C P I \frac{\hat{C}}{W}+\hat{n_{k}}(\lambda) r_{k}-\left(i^{*}+\pi\right) \hat{n_{f}}(\lambda)\right], \\
\Omega_{2}(\lambda)=\lambda^{2}\left[\tilde{n_{g}}(\lambda)^{2}+\tilde{n_{C}}(\lambda)^{2}+\sigma^{2} \tau^{2} \hat{e}(\lambda)^{2} \hat{n_{y}}(\lambda)^{2}+\hat{n_{k}}(\lambda)^{2}+\hat{n_{f}}(\lambda)^{2}\right] .
\end{gathered}
$$

Proof. We first write the bureaucrats' and consumers' constraints (Equations (22) and(34) which give us the separate dynamics of $d T(t)$ and $d W(t))$ :

$$
\begin{aligned}
\left.\mathrm{dW}(\mathrm{t})=\mathrm{W}(\mathrm{t})[1-\tau+\bar{x} \tau \hat{e}(\lambda)] \hat{n_{y}}(\lambda)-C P I \frac{\hat{C}}{W}+\hat{n_{k}}(\lambda) r_{k}-\left(i^{*}+\pi\right) \hat{n_{f}}(\lambda)\right] d t \\
+\mathrm{W}(\mathrm{t})\left[\sigma \tau \hat{e}(\lambda) \hat{n_{y}}(\lambda) d W^{W}+\hat{n_{k}}(\lambda) d u_{k}-\hat{n_{f}}(\lambda) d u_{f}\right], \\
d T(t)=T(t)\left[\hat{n_{g}}(\lambda)+\hat{n_{C}}(\lambda)\right] d t+T(t)\left[\tilde{n_{g}}(\lambda) d W^{g}(t)+\tilde{n_{C}}(\lambda) d W^{C^{G}}\right] .
\end{aligned}
$$

To obtain the dynamics of the ratio $\lambda(t)=W(t) / T(t)$, we use the Itô's lemma.

Itô's lemma. Let $\mathrm{X}(\mathrm{t})$ in $\mathbb{R}^{2}$ be a diffusion process and $\mathrm{F}(\mathrm{X})$ a $\mathbb{C}^{2}$ map from $\mathbb{R}^{2}$ to $\mathbb{R}$, then

$$
d F(X)=F_{x} d X+\frac{1}{2} d X^{\prime} F_{x x} d X
$$


with $F_{x}$ and $F_{x x}$ representing, respectively, the matrix of partial derivatives of $\mathrm{F}$ and the Hessian matrix.

We define $X=(T, W)^{\prime}, d X=(d T, d W)^{\prime}, F(X)=\frac{W}{T}$,

$$
\begin{gathered}
F_{x}=\left(\begin{array}{c}
\frac{\partial F}{\partial T} \\
\frac{\partial F}{\partial W}
\end{array}\right)=\left(\begin{array}{c}
\frac{-W}{T^{2}} \\
\frac{1}{T}
\end{array}\right), \\
F_{x x}=\left(\begin{array}{cc}
\frac{\partial^{2} F}{\partial T^{2}} & \frac{\partial^{2} F}{\partial T \partial W} \\
\frac{\partial^{2} F}{\partial W \partial T} & \frac{\partial^{2} F}{\partial W^{2}}
\end{array}\right)=\left(\begin{array}{cc}
\frac{2 W}{T^{3}} & \frac{-1}{T^{2}} \\
\frac{-1}{T^{2}} & 0
\end{array}\right) .
\end{gathered}
$$

From (41) we obtain

$$
d\left(\frac{W}{T}\right)=\frac{-W}{T^{2}} d T+\frac{1}{T} d W+\frac{W}{T^{3}} d T^{2}-\frac{1}{T^{2}} d T d W .
$$

We get the final form of Equation (40) by using the Levy characterization of diffusion processes and by considering the following properties of Wiener processes. Consider two Wiener processes $w_{i}$ and $w_{j}$. We have:

$$
\left(d w_{i}\right)^{2}=d t,<d t . d w_{i}>=0 \forall i \neq j, d t^{2}=0 .
$$

For purpose of simplicity, we assume the following correlation structure of two Wiener processes: $\left.d<w_{i}, w_{j}\right\rangle=0$, where $\left\langle w_{i}, w_{j}\right\rangle$ is the quadratic variation process for the components of the Wiener processes.

\subsection{Existence of a steady state distribution}

The concept of steady state for diffusion processes is defined in a stochastic sense. Instead of a point, $\lambda(t)$ converges to a set of values in a basin of attraction. This means that, once $\lambda$ has reached its long-term attractor $\lambda^{*}$, all the variables in the model which depend upon $\lambda$ will also reach their own basin of attraction. For Itô diffusion processes, the properties of the values in the basin of attraction of the variable of interest can be studied by constructing their distribution called the steady state distribution of the diffusion process. The issue here is therefore to study the convergence in distribution of the variable $\lambda(t)$. To do this, we use the mathematical tools of the theory of Markov chains to prove the existence and derive stationary probability measures. The techniques are similar to those used in a few papers dealing with continuous time stochastic growth models (see Bourguignon (1974), Merton (1975), Chang and Maliaris (1987), Jensen and Richter (2007)). 


\subsubsection{Asymptotic stochastic solutions of Itô diffusion processes}

We first recall some mathematical properties of steady state distributions of Itô diffusion processes (see Feller (1952), Feller (1954), Ito and McKean (1996)).

Let us consider the following SDE:

$$
d x=a(x) d t+b^{1 / 2}(x) d z, d z \approx N(0, d t), x \in[0, \infty],
$$

with $a(\cdot)$ and $b(\cdot)$ being continuous and differentiable functions of $x$.

Consider $X(t)$ the solution of the SDE and define the transition probability as

$$
P\left(x, t ; x_{0}, t_{0}\right)=\operatorname{Pr}\left[X(t) \leq x \mid X\left(t_{0}\right)=x_{0}\right] .(44)
$$

The probability density $\pi\left(x, t, x_{0}\right)$ satisfies the Kolmogorov-Fokker-Planck equation:

$$
\frac{1}{2} \frac{\partial^{2}}{\partial x^{2}}\left[b(x) \pi\left(x, t, x_{0}\right)\right]-\frac{\partial}{\partial x}\left[a(x) \pi\left(x, t, x_{0}\right)\right]=\frac{\partial \pi\left(x, t, x_{0}\right)}{\partial t} .
$$

The steady state density function, obtained by integrating (45), must satisfy

$$
p(x)=c_{1} m(x)+c_{2} S(x), p(x)=\lim _{t \rightarrow \infty} \pi\left(x, t, x_{0}\right),
$$

where

$$
M(x) \equiv \int_{x_{0}}^{x} m(u) d u, S(x) \equiv \int_{x_{0}}^{x} s(u) d u
$$

with

$$
m(x) \equiv \frac{\exp [2 J(x)]}{b(x)}, s(x) \equiv \exp [-2 J(x)], J(x) \equiv \int_{x_{0}}^{x} \frac{a(u)}{b(u)} d u .
$$

$c_{1}$ and $c_{2}$ are constants of integration ensuring that $p(x)$ is a true probability density. $s(x), S(x)$ and $m(x)$ are called, respectively, the scale density function, the scale function and the speed density function of the stochastic process $\mathrm{X}(\mathrm{t})$. 
Existence of steady state distribution. A time-invariant distribution function $P(x)$ exists if and only if

$$
\begin{aligned}
& \lim _{x \rightarrow 0} S(x)=\mp \infty \text { and } \mathrm{M}(\mathrm{x}) \text { is finite at the boundaries } 0 \text { and }+\infty, \\
& x \rightarrow \infty \\
& \text { i.e. } \lim x \rightarrow 0 \\
& \quad x \rightarrow \infty
\end{aligned}
$$

The existence of steady state distribution implies that the boundaries of the process are inaccessible. A corollary is that, if the boundaries are inaccessible, then $\pi\left(x, t, x_{0}\right)$ converges towards a probability density function defined by (46) with $c_{2}=0$ (for rigorous proofs, see Feller (1952), Feller (1954), Ito and McKean (1996)).

\subsubsection{A theorem of the existence of a steady state distribution for the wealth- to-tax revenues ratio $\lambda(t)$}

Now, we must prove that the boundaries 0 and $+\infty$ are inaccessible for the wealth-to-tax revenues ratio $\lambda(t)$. To do that, several preliminary remarks are in order.

First, $\lambda(t)$ is the ratio of two variables $W(t)$ and $T(t)$. We assume that $T \in(0,+\infty)$ and $W \in(0,+\infty)$. By assumption 0 is thus an inaccessible boundary for $W$ and $T$. This means that we do not consider the extreme situation in which corruption and tax evasion are so important that this yields a depletion of tax revenues $(T \rightarrow 0)$ and therefore entirely annihilates net wealth ( $W \rightarrow 0$, because of a high level of foreign debt).

Second, the fact that by assumption, $T$ and $W$ do not reach the zero boundary, does not mean that 0 and $+\infty$ are inaccessible for $\lambda$. Indeed,

$$
\text { for a finite } \mathrm{T}, \lim _{W \rightarrow+\infty} \lambda=+\infty \text {, and for a finite } \mathrm{W}, \lim _{T \rightarrow \infty} \lambda=0 .
$$

Therefore to prove that 0 and $+\infty$ are inaccessible boundaries for $\lambda$, a sufficient condition consists in proving that $+\infty$ is an inaccessible boundary for both $W$ and $T$.

Theorem 4.2. Let us consider the SDE of $T$ and $W$ in a compact form using the Levy characterization 


$$
d T(t)=a_{1}\left(T, \lambda^{*}\right) d t+b_{1}^{\frac{1}{2}}\left(\left(T, \lambda^{*}\right)\right) d w^{T},
$$

where

$$
\begin{gathered}
a_{1}\left(T, \lambda^{*}\right)=T(t)\left[n_{g}\left(\lambda^{*}\right)+n_{C}\left(\lambda^{*}\right)\right]=T(t) a\left(\lambda^{*}\right), \\
b_{1}\left(T, \lambda^{*}\right)=T^{2}(t)\left[\tilde{n}_{g}^{2}\left(\lambda^{*}\right)+\tilde{n}_{C}^{2}\left(\lambda^{*}\right)\right]=T^{2}(t) b\left(\lambda^{*}\right), \\
d W(t)=d_{1}\left(W, \lambda^{*}\right) d t+h_{1}^{\frac{1}{2}}\left(\left(W, \lambda^{*}\right)\right) d z^{W},
\end{gathered}
$$

where

$$
\begin{aligned}
& d_{1}\left(W, \lambda^{*}\right)=W(t)\left[\left[1-\tau+\bar{x} \tau \hat{e}\left(\lambda^{*}\right)\right] \hat{n}_{y}\left(\lambda^{*}\right)-C P I \frac{\hat{C}}{W}+\right. \\
& \left.\hat{n}_{k}\left(\lambda^{*}\right) r_{k}-\left(i^{*}+\pi\right) \hat{n}_{f}\left(\lambda^{*}\right)\right]=W(t) d\left(\lambda^{*}\right), \\
& h_{1}\left(W, \lambda^{*}\right)=W^{2}(t)\left[\sigma^{2} \tau^{2} \hat{e}\left(\lambda^{*}\right)^{2} \hat{n}_{y}^{2}\left(\lambda^{*}\right)+\hat{n}_{k}^{2}\left(\lambda^{*}\right)+\hat{n}_{f}^{2}\left(\lambda^{*}\right)\right]=W^{2}(t) h\left(\lambda^{*}\right) .
\end{aligned}
$$

Sufficient conditions for the existence of a steady state distribution for the ratio of wealth-to-fiscal revenue are:

$$
\text { a) } 2 a\left(\lambda^{*}\right)-b\left(\lambda^{*}\right)<0 \text {, and b) } 2 d\left(\lambda^{*}\right)-h\left(\lambda^{*}\right)<0
$$

\section{Proof. i)}

We first prove that $\lim _{T \rightarrow+\infty} S\left(T, \lambda^{*}\right)=+\infty$

Using the Levy representation of the SDE of $T$, as given in the theorem, we compute the scale density function of $T(t)$ as

$$
s\left(T, \lambda^{*}\right)=\exp \left\{-2 \int_{T_{0}}^{T} \frac{a_{1}\left(u, \lambda^{*}\right)}{b_{1}\left(u, \lambda^{*}\right)} d u\right\}, T_{0}=T(0),
$$

or

$$
s\left(T, \lambda^{*}\right)=\exp \left\{-2 \frac{a\left(\lambda^{*}\right)}{b\left(\lambda^{*}\right)} \int_{T_{0}}^{T} \frac{1}{u} d u\right\}=\left[\frac{T}{T_{0}}\right]^{-2 \frac{a(\lambda *)}{b\left(\lambda^{*}\right)}}
$$

Then, we calculate the scale function

$$
S\left(T, \lambda^{*}\right)=\int_{T_{0}}^{T} s(u) d u=\frac{b\left(\lambda^{*}\right)\left(T_{0}\right)^{\frac{2 a\left(\lambda^{*}\right)}{b\left(\lambda^{*}\right)}}}{-2 a\left(\lambda^{*}\right)+b\left(\lambda^{*}\right)}\left\{[T]^{\frac{-2 a\left(\lambda^{*}\right)+b\left(\lambda^{*}\right)}{b\left(\lambda^{*}\right)}}-\left[T_{0}\right]^{\frac{-2 a\left(\lambda^{*}\right)+b\left(\lambda^{*}\right)}{b\left(\lambda^{*}\right)}}\right\},
$$


We see that

$$
\lim _{T \rightarrow+\infty} S\left(T, \lambda^{*}\right)=+\infty, \text { if } 2 a\left(\lambda^{*}\right)-b\left(\lambda^{*}\right)<0 .
$$

ii)

Using a similar approach by considering the SDE of $\mathrm{W}(\mathrm{t})$, we get

$$
\lim _{W \rightarrow+\infty} S\left(W, \lambda^{*}\right)=+\infty, \text { if } 2 d\left(\lambda^{*}\right)-h\left(\lambda^{*}\right)<0
$$

Remark 1. Condition b) in (51) means that to avoid an infinite increase of wealth, the risk-adjusted return of net wealth must be capped, which implies that the risk-adjusted return of tax evasion and the marginal productivity of capital should not exceed a threshold value, and that the cost of borrowing abroad cannot be too low. Condition a) implies that there is a minimal risk associated to fiscal evasion and corruption. Indeed, would they be no risk for corrupted bureaucrats and frauding taxpayers, no tax revenues would be left to finance public spending. It would lead to the extreme case described in section 4.2.2.

\subsection{Invariant density function for the external debt-to-fiscal revenues ratio}

Theorem 4.3. Let $f(\lambda)$ be the invariant steady-state density function of $\lambda(t)$. Assume that $T>0, W>0$ and that the conditions a) and b) of Theorem 4.2 hold. Then, $f(\lambda)$ for the SDE of the wealth-to-fiscal revenues ratio

$$
\begin{gathered}
d \lambda(t)=\Omega_{1}(\lambda) d t+\Omega_{2}^{\frac{1}{2}}(\lambda) d B(t), \\
\Omega_{1}=K_{2}^{*} \lambda=\lambda\left[\tilde{n}_{g}^{2}(\lambda)+\tilde{n}_{C}^{2}(\lambda)-\hat{n}_{g}(\lambda)-\hat{n}_{C}(\lambda)+[1-\tau+\bar{x} \tau \hat{e}(\lambda)] \hat{n}_{y}(\lambda)-\right. \\
\left.C P I \frac{\hat{C}}{W}+\hat{n}_{k}(\lambda) r_{k}-\left(i^{*}+\pi\right) \hat{n}_{f}(\lambda)\right], \\
\Omega_{2}=K_{3}^{*} \lambda^{2}=\lambda^{2}\left[\tilde{n}_{g}^{2}(\lambda)+\tilde{n}_{C}^{2}(\lambda)+\sigma^{2} \tau^{2} \hat{e}^{2}(\lambda) \hat{n}_{y}^{2}(\lambda)+\hat{n}_{k}^{2}(\lambda)+\hat{n}_{f}^{2}(\lambda)\right]
\end{gathered}
$$

is

$$
\begin{aligned}
f(\lambda) & =C_{0} m(\lambda)=\frac{1-2 \frac{K_{2}^{*}}{K_{3}^{*}}\left(\frac{\lambda}{\tilde{\lambda}}\right)^{-2\left(1-\frac{K_{2}^{*}}{K_{3}^{*}}\right)}}{\frac{\alpha-1}{\tilde{\tilde{\lambda}}}\left(\frac{\lambda}{\tilde{\lambda}}\right)^{-\alpha}},
\end{aligned}
$$


$\alpha=2\left(1-K_{2}^{*} / K_{3}^{*}\right), \tilde{\lambda}$ is an arbitrary $\lambda$ defined as the lower bound from which the power-law holds.

Proof.

We compute the speed density function as

$$
m(\lambda)=\frac{\exp (2 J(\lambda))}{\Omega_{2}(\lambda)}, \quad J(\lambda)=\int_{\tilde{\lambda}}^{\lambda} \frac{\Omega_{1}(u)}{\Omega_{2}(u)} d u,
$$

We therefore get

$$
\begin{aligned}
& C_{0} m(\lambda)=C_{0} \frac{1}{K_{3}^{*} \lambda^{2}} \exp \left[2 \int_{\tilde{\lambda}}^{\lambda} \frac{K_{2}^{*} u}{K_{3}^{*} u^{2}} d u\right] \\
& =C_{0} \frac{1}{K_{3}^{*} \lambda^{2}} \exp \left[2 \int_{\hat{\lambda}}^{\lambda} \frac{k_{2}^{*}}{K_{3}^{*} u} d u\right] \\
& =C_{0} \frac{1}{K_{3}^{*} \lambda^{2}} \exp \left[2 \frac{K_{2}^{*}}{K_{3}^{*}} \ln \left(\frac{\lambda}{\tilde{\lambda}}\right)\right] \\
& =\quad C_{0} \frac{1}{K_{3}^{*} \lambda^{2}}\left[\frac{\lambda}{\bar{\lambda}}\right]^{2 \frac{K_{2}^{*}}{K_{3}^{*}}} \\
& =\quad \frac{C_{0} \tilde{\lambda}^{-2}}{K_{3}^{*}}\left(\frac{\lambda}{\tilde{\lambda}}\right)^{-2\left(1-\frac{K_{2}^{*}}{K_{3}^{*}}\right)}
\end{aligned}
$$

This corresponds to a power-law with $\alpha=2\left(1-K_{2}^{*} / K_{3}^{*}\right)$.

We then calculate the normalizing constant $C_{0}$, such that $\int_{\tilde{\lambda}}^{+\infty} f(u) d u=$ 1. This yields $C_{0}=-\tilde{\lambda}\left(2 K_{2}^{*}-K_{3}^{*}\right)$. By replacing in the expression above, we get $f(\lambda)$.

The $\mu^{t h}$-order moment is given by

$$
\int_{\tilde{\lambda}}^{+\infty} u^{\mu} f(u) d u=\frac{\alpha-1}{\alpha-1-\mu} \tilde{\lambda}^{\mu} .
$$

All moments, except the mean, diverge when $2<\alpha<3$. This means that they do not converge as more observations are added to the sample and that the distribution has time-varying tails.

In the expression of $\alpha, K_{2}^{*}$ and $K_{3}^{*}$ refer respectively to the mean and volatility of net wealth. The effect of a change in a parameter of the model on the shape parameter thus depends upon a trade-off between the mean level of wealth and its variability. One cannot exclude to have nonlinear effects depending upon the respective response of the mean and variance component of wealth to changes in the parameters. Rather than perform analytical exercises, we do some simulations of the model. 


\subsection{Some simulations of the model}

We now simulate the model to examine the impact of tax evasion and corruption on the scale parameter $\alpha$. Since the shape parameter is positive (by definition of a power-law function), the ratio $\left(K_{2}^{*} / K_{3}^{*}\right)$ varies in the interval $(-\infty, 1)$. When $\left(K_{2}^{*} / K_{3}^{*}\right)$ varies from $-\infty$ to $1, \alpha$ decreases, thereby implying that the pdf of $\lambda$ will tend to Pareto laws as the ratio diminishes. This ratio can be interpreted as the combined net returns of illegal activities (fraud and corruption) relative to their risk. Since, we have seen that net wealth and debt are negatively correlated, one can understand that, an increase in the returns to illegal activity relative to their risk implies heavier tails in the pdf of the external debt ratio and therefore a higher likelihood of the occurrence of extreme debt events.

We first calibrate the model to have a benchmark situation (baseline scenario). The macroeconomic variables are chosen in such a way to simulate an economy with some plausible macroeconomic characteristics of emerging economies. The aggregate income is assumed to be 1000 billion dollars with aggregate tax revenues of 400 billions. The share of tax revenues over total wealth is $50 \%$. The marginal productivity of capital is $5 \%$ and the interest rate on external debt is 7\%. Corrupt bureaucrats steal $30 \%$ of tax revenues, tax evaders hide $10 \%$ of their income. The probability to be caught as a tax fraudulent is one-half, the probability of being a corrupt bureaucrat is 0.5 . If they are caught, the consumer/tax evader must pay a penalty of $20 \%$ of the hidden income. The values of the other parameters (variances, tax rate, and the parameters computed from the calibrated variables) are given below (see Table 3).

\section{Impact of fighting fiscal evasion on the shape parameter}

Fighting against fiscal evasion reduces the frequency of extreme events of external debt (see Figure 4). This happens for a higher probability $p$ of catching those consumers convinced of fraud, or a higher penalty rate $b$. A corollary result is that tax avoidance have more negative repercussions on foreign debt (with more heavy tails indicating more frequent extreme events), if the evaders take advantage of favorable conditions: deficiencies of administrative surveillance, opaque fiscal environment.

Meanwhile, as the figures suggest, a highly punitive system can create a harmful situation in terms of debt. Indeed, the inverted bell curves (especially for $b$ ) suggest that, above a given threshold, there may be a fiscal cost 


\begin{tabular}{|c|c|c|c|c|c|}
\hline & Shape parameter $\alpha=2\left(1-K_{2} / K_{3}\right)$ & 2,80 & & & \\
\hline$K_{2}$ & & $-9,69$ & & Characteristics of the Economy & \\
\hline$K_{3}$ & & 24,12 & $\mathrm{y}$ & aggregate revenue & 1000 \\
\hline & Fiscal evasion & & $\mathrm{T}$ & aggregate tax revenue & 400 \\
\hline $\mathrm{e}$ & Share of the household's concealed revenue & 0.1 & $T / W$ & share of tax revenue on aggregate wealth & 0,5 \\
\hline $\bar{x}$ & $\begin{array}{l}\mathbb{E} \text { of the yield of a concealed unit of taxed revenue } \\
\text { Administration's fight against fiscal evasion }\end{array}$ & 0,4 & $\begin{array}{c}C / W \\
\beta\end{array}$ & $\begin{array}{l}=n_{c} * T / W \\
\text { coeff. of the production function (on } \mathrm{k} \text { ) }\end{array}$ & $\begin{array}{c}0,10 \\
0,5\end{array}$ \\
\hline$\tau$ & Tax rate & 0,1 & $\mu$ & Arrow Prat coefficient & -20 \\
\hline $\mathrm{p}$ & Probability of being caught by the administration & 0,5 & CPI & CPI index $=P^{1-\eta}$ & 100 \\
\hline b & Fine HH has to pay if caught by the administration & 0,2 & $r_{k}$ & interest rate on capital & 0,05 \\
\hline $\bar{g}$ & $\begin{array}{c}\mathbb{E} \text { of taxes (legally collected) } \\
\text { Corruption }\end{array}$ & 249,0 & $r_{f}$ & $=i *+\pi$ (interest rate on external debt) & 0,07 \\
\hline theta $\theta$ & Share of tax ceased by the corrupted government & 0,3 & $n_{g}$ & $g_{\text {bar }(t)} / T$ & 0,8 \\
\hline p1 & $\begin{array}{c}\text { Probability of the government to be corrupted } \\
\text { Volatilities }\end{array}$ & 0,5 & $\begin{array}{c}n_{c} \\
n_{K}\end{array}$ & $\begin{array}{l}C^{G_{b} a r} / T=1-n_{g} \\
K / W \text { given by } n_{k}^{\beta}=n_{y} /\left(n_{g} T / W\right)^{1-\beta}\end{array}$ & $\begin{array}{l}0,2 \\
3,9\end{array}$ \\
\hline$\sigma$ & variance of the consumer's lottery & 0,6 & $n_{f}$ & $P D / W=n_{K}-1$ & 2,9 \\
\hline $\begin{array}{l}\sigma_{W w} \\
\sigma_{W k}\end{array}$ & $\begin{array}{l}\text { variance on concealed revenue not ceased by the gvt } \\
\text { variance of the growth of return to capital } d R_{k}\end{array}$ & 1 & $\begin{array}{c}n_{y} \\
n_{g}^{\text {tilde }} \\
t_{\text {tilde }}\end{array}$ & $=y / W=y T / W / T$ & $\begin{array}{l}1,25 \\
0,63\end{array}$ \\
\hline$\sigma_{W f}$ & variance of the growth of $i_{t}$ on external debt $d R_{f}$ & 1 & $n_{c}^{g}$ tilde & & 0,16 \\
\hline
\end{tabular}

Table 3: Calibration of the parameters for the computation of the shape parameter $\alpha$ Note: in blue: coefficients or parameters fixed for the calibration

in orange: coefficients or parameters computed

for the government: the higher the penalty rate, the more consumers will try to figure out ways to stop paying their income tax. Such a nonlinear effect is in line with the literature suggesting that there is no compelling evidence of how tax compliance is affected by punishment through more efficient tax audits, or tax penalties (see Alm (2012), Murphy (2008), Slemrod (2007)).

The fact that a severe punishment may increase the way people behave in not fulfilling their tax obligations (thereby implying here a higher foreign debt level) has been motivated by different arguments. First, people do not necessarily report their tax liabilities on the basis of legal obligations, but in good faith according to what they believe to be correct. High penalty rate can be though of as reflecting abusive transactions between the tax administration and tax payers, especially if government officials are known to be corrupted (they respond to tax fraud by ratcheting up penalties). A second explanation is more in line with our model. The penalty regime does affect the taxpayer's behavior. Here the tax evaders pays twice: a fixed penalty of the evaded tax (provided they are caught), plus an interest rate on debt (they internalize the effect of fraud on debt, because this reduces their net wealth). The fact that they bear this additional interest rate cost should persuade the consumers to limit their tax noncompliance below a certain level (if the amount of debt service paid from foreign borrowing increases, their compliance rate is likely to rise). In this context, attempts by the government to coerce and threaten taxpayers into compliance through high penalty rates 
could undermine the legitimacy of the tax administration's authority.
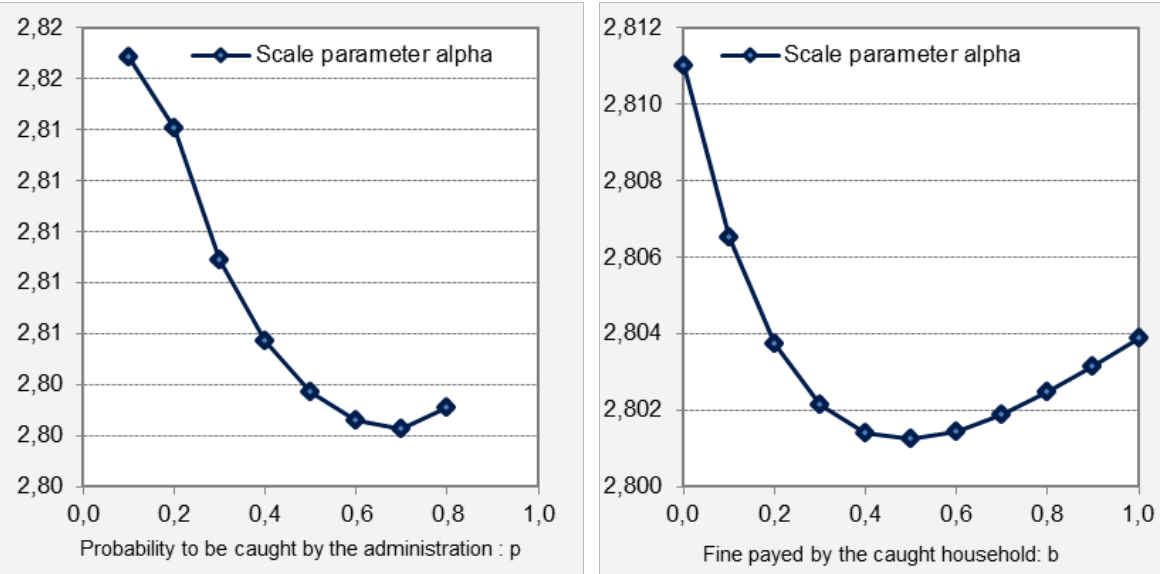

Figure 4: Simulations: impact of changes in $p, b$ on $\alpha$

\section{Impact of corruption on the shape parameter}

Figure 5 suggests that more corrupt bureaucrats (increase in $p_{1}$ ) and a higher tax diversion (increase in $\theta$ ) imply a thiner tail on the pdf of $\lambda(\alpha$ increases) and therefore more frequent extreme events for the external debt ratio.

The negative harmful effects are, however, reversed when the share of resources stolen becomes higher above a certain threshold. The humped curve representing a nonlinear relationship between $\alpha$ and $\theta$ suggests that tax diversion of tax resources can have de-stabilizing or stabilizing effects on foreign indebtedness (stabilizing meaning a lower likelihood of adverse high debt scenarios in the right-hand side of the pdf of the external debt ratio, that is a decrease in $\alpha$ ). An increase in $\theta$ biases the composition of spending by raising the share of unproductive spending relative to productive spending. The country needs to borrow more from abroad and the mean net wealth (expressed as share of total taxes) diminishes (portfolio-adjustment effect). But, as $\theta$ takes higher values, the expected lifetime path of returns from corruption becomes more decreasing (the bureaucrats exhaust rapidly their corruption opportunity). This contributes to stabilize foreign borrowing. 

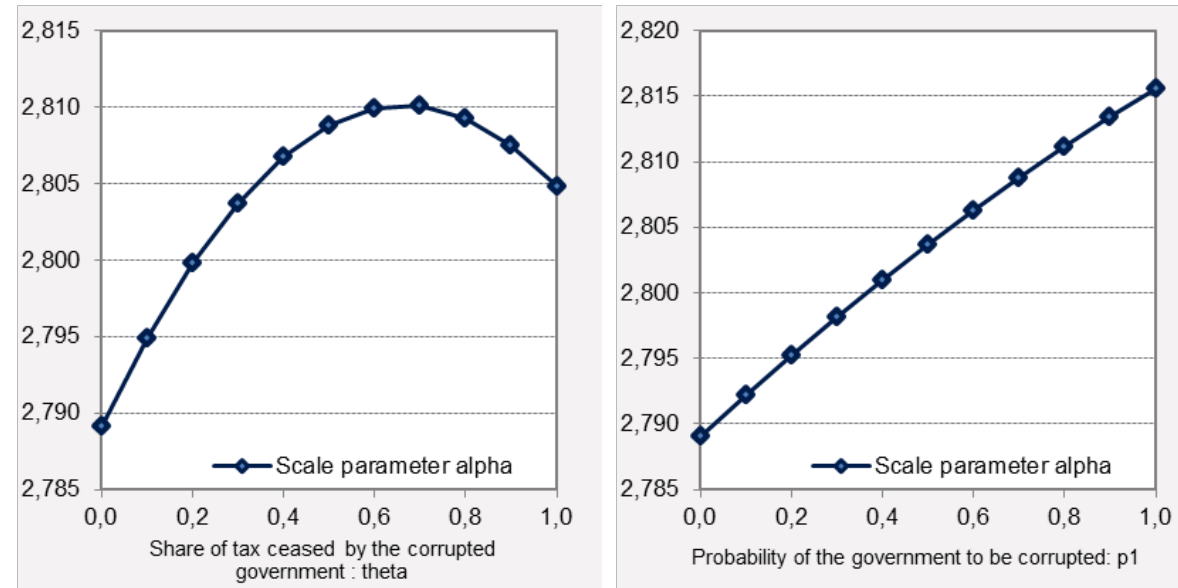

Figure 5: Simulations: impact of changes in $\theta, p_{1}$ on $\alpha$

\section{Conclusion}

Our intention in this paper has been to suggest that the emerging countries' external debt ratio can well be described by power-law distributions, and to close the gap between the empirical evidence and the theoretical framework within which such power-law functions can be obtained analytically. We consider the role of corruption and tax evasion about which there is still much to learn concerning their implications on the emerging countries' debt crises or debt stress episodes.

Our claim that foreign debt ratio can be the outcome of Pareto laws is obtained rigorously, by using econometric tests rather than simply plotting log-log graphs of the presumed distributions of the data. This is important, since a non-negligible amount of empirical papers estimates shape parameters by assuming that the distribution is a Pareto law, while this assumption needs to be tested formally.

Our purpose was then to provide a simple illustration of how a corrupt economy with tax evasion might explain this empirical observation. Our model incorporates the essential features of emerging economies: foreign aid and borrowing is often a substitute to domestic taxation, bureaucrats officially appointed to make tax audits are sometimes inclined to seek private ways of using the collected tax rather than leaving them available for productive investment, the detection of illegal taxation activities by the governments 
is not necessarily efficient. Though they are present in the model, for sake of completeness, our analysis is not meant to consider the role of macroeconomic shocks such as terms of trade, supply shocks, interest rates shock on foreign debt. We prefer to focus on the role of endogenous uncertainty, meaning that the tails of the Pareto law do not only depend upon the stochastic components of the diffusion processes, but also on the probability of detecting fraudulent people and their risk-taking behavior, on the probability of facing a corrupt bureaucrat and on the risk-taking behavior of bureaucrats.

This paper could be extended by investigating other distributions that are likely to characterize foreign debt, notably the family of upper incomplete Gamma distributions. Enriching the class of distributions for external debt would help in the detection of early warning stress debt episodes in the emerging countries.

\section{Appendix A. Government's optimal choice}

This appendix and the next ones present how the government's and household's optimal choices are calculated. The methodology is based on techniques used in continuous time optimization models (see for instance Chang (2004), Turnovsky (1999), Turnovsky (2000)).

The government's choice is as follows:

$$
\begin{gathered}
\max _{\bar{C}^{G}(t)}=\mathbb{E} \int_{0}^{+\infty} \frac{1}{\gamma} \bar{C}^{G}(t)^{\gamma} e^{-\rho t} d t \\
\text { subject to } \\
d T(t)=\left[\frac{\bar{g}(t)}{T(t)}+\frac{\overline{C^{G}(t)}}{T(t)}\right] T(t) d t+\left[\frac{\tilde{g} d W^{g}(t)}{T(t)}+\frac{\tilde{C^{G}} d W^{C^{G}}(t)}{T(t)}\right] T(t) .
\end{gathered}
$$

This constraint can be expressed as:

$$
\frac{d T(t)}{T(t)}=\psi^{T} d t+\sigma_{w^{T}} d w^{T}
$$

with

$$
\begin{aligned}
\psi^{T} & =\frac{\bar{g}(t)}{T(t)}+\frac{\overline{C^{G}}(t)}{T(t)} \\
\sigma_{w^{T}} d w^{T} & =\frac{\tilde{g} d W^{g}(t)}{T(t)}+\frac{\tilde{C^{G}} d W^{C} G}{T(t)} .
\end{aligned}
$$


Let us define $n_{g}=\frac{\bar{g}(t)}{T(t)}, n_{C}=\frac{\overline{C^{G}(t)}}{T(t)}, \tilde{n_{g}}=\frac{\tilde{g}}{T(t)}$ and $\tilde{n_{C}}=\frac{\tilde{C^{G}}}{T(t)}$. We then have:

$$
\begin{aligned}
\psi^{T} & =n_{g}+n_{C}, \\
\sigma_{w^{T}} d w^{T} & =\tilde{n_{g}} d W^{g}(t)+\tilde{n_{C}} d W^{C^{G}}(t),
\end{aligned}
$$

such that

$$
\sigma_{w^{T}}^{2}={\tilde{n_{g}}}^{2} \sigma_{W^{g}}^{2}+{\tilde{n_{C}}}^{2} \sigma_{W^{C}}^{2}
$$

The program becomes

$$
\begin{aligned}
\max _{n^{G}, n^{C}}=\mathbb{E} \int_{0}^{+\infty} \frac{1}{\gamma}\left(T n_{C}\right)^{\gamma} e^{-\rho t} d t \\
\text { subject to } \\
\frac{d T(t)}{T(t)}=\psi^{T} d t+\sigma_{w^{T}} d w^{T}, \\
1=n_{g}+n_{C} .
\end{aligned}
$$

The differential generator of the value function $\mathrm{V}(\mathrm{T}, \mathrm{t})$ is defined by:

$$
L[V(T, t)] \equiv \frac{\partial V}{\partial t}+\psi^{T} T \frac{\partial V}{\partial T}+\frac{1}{2} \sigma_{w^{T}}^{2} T^{2} \frac{\partial^{2} V}{\partial T^{2}} .
$$

We assume $\mathrm{V}$ to be of the following time separable form:

$$
V(T, t)=e^{-\rho t} X(T)
$$

And government choses $n_{C}$ and $n_{g}$ maximising the following Lagrangian:

$$
\text { Lagrangian }=e^{-\rho t} \frac{1}{\gamma}\left(T n_{C}\right)^{\gamma}+L\left[e^{-\rho t} X(T)\right]+e^{-\rho t} \lambda\left(1-n_{g}-n_{C}\right) .
$$

The partial derivative with respect to $n_{C}$ is:

$$
T^{\gamma} n_{C}^{\gamma-1}+T X_{T}-T^{2} X_{T T} \sigma_{W^{C} G}^{2} n_{C}=\lambda
$$

The partial derivative with respect to $n_{g}$ is:

$$
T X_{T}-T^{2} X_{T T} \sigma_{W g}^{2} n_{g}=\lambda .
$$

Putting these equations together with $1=n_{g}+n_{C}$ leads to:

$$
T^{\gamma} n_{C}^{\gamma-1}=T^{2} X_{T T}\left[\sigma_{W^{C}}^{2} n_{C}-\sigma_{W^{g}}^{2} n_{g}\right]
$$


and

$$
T^{\gamma} n_{C}^{\gamma-1}=T^{2} X_{T T}\left[\left(\sigma_{W^{C}}^{2}+\sigma_{W^{g}}^{2}\right) n_{C}-\sigma_{W^{g}}^{2}\right] .
$$

Besides, the value function must satisfy the Bellman equation

$$
\max _{n_{C}, n_{g}}\left\{\frac{1}{\gamma} e^{-\rho t}\left(T n_{C}\right)^{\gamma}+L\left[e^{-\rho t} X(T)\right]\right\}=0 .
$$

To solve it, we substitute the optimized value of $n_{C}$ and $n_{g}$ :

$$
\frac{1}{\gamma} T^{\gamma} \hat{n_{C}^{\gamma}}-\rho X(T)+T X_{T}+\frac{1}{2} \sigma_{w^{T}}^{2} T^{2} X_{T T}=0 .
$$

To solve the resulting equation in $\mathrm{X}(\mathrm{T})$, we postulate $\mathrm{X}(\mathrm{T})$ of the form:

$$
X(T)=\delta T^{\gamma}
$$

with $\delta$ to be determined. This yields to

$$
\begin{aligned}
T X_{T} & =\gamma X(T), \\
T^{2} X_{T T} & =\gamma(\gamma-1) X(T) .
\end{aligned}
$$

Using this, the Bellman equation becomes:

$$
\frac{1}{\gamma} T^{\gamma} \hat{n_{C}^{\gamma}}-\rho X(T)+\gamma X(T)+\frac{1}{2} \sigma_{w^{T}}^{2} \gamma(\gamma-1) X(T)=0 .
$$

According to (A.15), $\left(T \hat{n_{C}}\right)^{\gamma-1}$ is given by:

$$
\begin{aligned}
T^{\gamma} n_{C}^{\gamma-1} & =T^{2} X_{T T}\left[\left(\sigma_{W^{C} G}^{2}+\sigma_{W^{g}}^{2}\right) n_{C}-\sigma_{W^{g}}^{2}\right] \\
& =\gamma(\gamma-1)\left[\left(\sigma_{W^{C}}^{2}+\sigma_{W^{g}}^{2}\right) n_{C}-\sigma_{W^{g}}^{2}\right] X(T) .
\end{aligned}
$$

We can substitute it in (A.20) and divide by $X(T)$ :

$$
\left(\sigma_{W^{C}}^{2}+\sigma_{W^{g}}^{2}\right){\hat{n_{C}}}^{2}-\sigma_{W^{g}}^{2} \hat{n_{C}}+\frac{\rho-\gamma}{1-\gamma}+\frac{1}{2} \sigma_{w^{T}}^{2} \gamma=0
$$

which leads to the second-order differential equation with:

$$
\triangle=\sigma_{W^{g}}^{4}-4\left(\sigma_{W^{C}}^{2}+\sigma_{W^{g}}^{2}\right)\left(\frac{\rho-\gamma}{1-\gamma}+\frac{1}{2} \sigma_{w^{T}}^{2} \gamma\right) .
$$

Solutions (if $\triangle$ is positive) are of the form

$$
\hat{n_{C}}=\frac{\sigma_{W^{g}}^{2} \pm \sqrt{\triangle}}{2\left(\sigma_{W^{C}}^{2}+\sigma_{W^{g}}^{2}\right)} .
$$

With $\hat{n_{C}}$ positive we have

$$
\hat{n_{C}}=\frac{\sigma_{W^{g}}^{2}+\sqrt{\sigma_{W^{g}}^{4}-4\left(\sigma_{W^{C}}^{2}+\sigma_{W^{g}}^{2}\right)\left(\frac{\rho-\gamma}{1-\gamma}+\frac{1}{2} \sigma_{w^{T}}^{2} \gamma\right)}}{2\left(\sigma_{W^{C}}^{2}+\sigma_{W^{g}}^{2}\right)} .
$$




\section{Appendix B. The consumer's optimal choice}

Government and households are assumed to have the same time preference coefficient $\rho$ ). The objective function is

$$
\max _{C^{P}, C^{M}, e, n_{K}, n_{f}}=\mathbb{E} \int_{0}^{+\infty} \frac{1}{\mu}\left[C^{P}(t)^{\eta} C^{M}(t)^{1-\eta}\right]^{\mu} e^{-\rho t} d t .
$$

The household maximizes the intertemporal utility function subject to the constraints given by Equation (34), and with $W(0)=w_{0}$.

We define the aggregate consumption $C=C^{P}(t)^{\eta} C^{M}(t)^{1-\eta}$. The consumer price index can be defined as $C P I(t)=P^{P}(t)^{\eta} P(t)^{1-\eta}$ which yields to $C P I(t)=P(t)^{1-\eta}$, as the domestic good is the numeraire

We thus have:

$$
\frac{d W(t)}{W(t)}=\psi^{W} d t+\sigma_{z^{W}} d z^{W}
$$

with

$$
\begin{aligned}
\psi^{W} & =[1-\tau+\bar{x} \tau e(t)] n_{k}^{\beta} n_{g}^{1-\beta}\left(\frac{T}{W}\right)^{1-\beta}-\frac{C P I(t) C(t)}{W}+n_{k} r_{k}-\left(i^{*}+\pi\right) n_{f}, \\
\sigma_{z^{W}} d z^{W} & =\sigma \tau e(t) n_{k}^{\beta} n_{g}^{1-\beta}\left(\frac{T}{W}\right)^{1-\beta} d W^{W}(t)+n_{k} d u_{k}-n_{f} d u_{f},
\end{aligned}
$$

where $n_{k}=\frac{k}{W}$ and $n_{f}=\frac{P D}{W}\left(0<n_{k}<1\right.$ and $\left.n_{f}>0\right)$.

And we get

$$
\sigma_{z^{W}}^{2}=\sigma^{2} \tau^{2} e(t)^{2} n_{k}^{2 \beta} n_{g}^{2(1-\beta)}\left(\frac{T}{W}\right)^{2(1-\beta)} \sigma_{W^{W}}^{2}+n_{k}^{2} \sigma_{W^{k}}^{2}+n_{f}^{2} \sigma_{W^{f}}^{2} .
$$

The households' decision is as follows:

$$
\begin{gathered}
\max _{C, e, n_{K}, n_{f}} \mathbb{E} \int_{0}^{+\infty} \frac{1}{\mu} C^{\mu} e^{-\rho t} d t, \text { with }-\infty<\mu<1, \rho>0 \\
\text { subject to } \\
\frac{d W(t)}{W(t)}=\psi^{W} d t+\sigma_{z^{W}} d z^{W} \\
n_{K}-n_{f}=1, \\
W(0)=w_{0} .
\end{gathered}
$$


Define $\mathrm{V}$ as the value function

$$
V(W)=\max _{C, e, n_{K}, n_{f}} \mathbb{E} \int_{0}^{+\infty} \frac{1}{\mu} C^{\mu} e^{-\rho t} d t
$$

Then, the optimal program satisfies the Hamilton Jacobi Bellman equation

$$
\rho V(W)=\max _{C, e, n_{K}, n_{f}} \tilde{F}\left(C, e, n_{k}, n_{f}\right)=\max _{C, e, n_{K}} F\left(C, e, n_{k}\right),
$$

where

$$
F\left(C, e, n_{k}\right)=\frac{1}{\mu} C^{\mu}+V^{\prime}(W) W \psi^{W}+\frac{1}{2} V^{\prime \prime}(W) W^{2} \sigma_{z^{W}}^{2} .
$$

Using (B.7), which implies $n_{f}=n_{K}-1$, we get the following necessary conditions:

$$
\begin{gathered}
\frac{\partial F(.)}{\partial C}=C^{\mu-1}-C P I V^{\prime}(W)=0, \\
\frac{\partial F(.)}{\partial e}=\begin{array}{c}
\bar{x} \tau n_{k}^{\beta} n_{g}^{1-\beta}\left(\frac{T}{W}\right)^{1-\beta} W V^{\prime}(W) \\
+\sigma^{2} \tau^{2} e(t) n_{k}^{2 \beta} n_{g}^{2(1-\beta)}\left(\frac{T}{W}\right)^{2(1-\beta)} \sigma_{W^{W}}^{2} W^{2} V^{\prime \prime}(W)=0,
\end{array} \\
\frac{\partial F(.)}{\partial n_{k}}=\left[\begin{array}{l}
\left.\beta[1-\tau+\bar{x} \tau e(t)] n_{k}^{\beta-1} n_{g}^{1-\beta}\left(\frac{T}{W}\right)^{1-\beta}+r_{k}-\left(i^{*}+\pi\right)\right] W V^{\prime}(W) \\
+\left[\beta \sigma^{2} \tau^{2} e(t)^{2} n_{k}^{2 \beta-1} n_{g}^{2(1-\beta)}\left(\frac{T}{W}\right)^{2(1-\beta)} \sigma_{W^{W}}^{2}+n_{k} \sigma_{W^{k}}^{2}+\left(n_{k}-1\right) \sigma_{W^{f}}^{2}\right] W^{2} V^{\prime \prime}(W)=0 .
\end{array}\right.
\end{gathered}
$$

F has an extremum $\left(\hat{C}, \hat{e}, \hat{n_{k}}\right)$ defined such as to verify the last three equations. From the first two variables we obtain:

$$
\begin{gathered}
\hat{C}=\left(C P I V^{\prime}(W)\right)^{\frac{1}{\mu-1}}, \\
\hat{e}=\frac{\bar{x} \tau \hat{n_{k}} n_{g}^{1-\beta}\left(\frac{T}{W}\right)^{1-\beta}}{A R(W)\left(\sigma \tau{\hat{n_{k}}}^{\beta} n_{g}^{1-\beta}\left(\frac{T}{W}\right)^{1-\beta} \sigma_{W} W\right)^{2}},
\end{gathered}
$$

with $A R(W)$ being the Arrow Prat relative risk coefficient defined by $A R(W)=$ $\frac{-W V^{\prime \prime}(W)}{V^{\prime}(W)}$.

Assuming $\mathrm{V}$ has the form $V(W)=\delta W^{\mu}$, where $\delta$ is a constant, we get 
$A R(W)=(1-\mu)$ constant.

The third equation leads to

$$
\begin{aligned}
& \beta[1-\tau+\bar{x} \tau \hat{e}]\left(\frac{T}{W}\right)^{1-\beta} W V^{\prime}(W) n_{g}^{1-\beta} n_{k}^{\beta} \\
& +\beta \sigma^{2} \tau^{2} \hat{e}^{2}\left(\frac{T}{W}\right)^{2(1-\beta)} \sigma_{W^{W}}^{2} W^{2} V^{\prime \prime}(W) n_{g}^{2(1-\beta)} n_{k}^{2 \beta} \\
& +\left[n_{k}^{2}\left(\sigma_{W^{k}}^{2}+\sigma_{W^{f}}^{2}\right)-n_{k} \sigma_{W^{f}}^{2}\right] W^{2} V^{\prime \prime}(W) \\
& +\left[r_{k}-\left(i^{*}+\pi\right)\right] W V^{\prime}(W) n_{k}=0 .
\end{aligned}
$$

Define $n_{y}$ as the share of production over total wealth, that is $n_{y}=\frac{Y}{W}$. We then have $n_{g}^{1-\beta} n_{k}^{\beta}\left(\frac{T}{W}\right)^{1-\beta}=n_{y}$, which leads to rewrite the condition as follows

$$
\begin{aligned}
& \beta[1-\tau+\bar{x} \tau \hat{e}] W V^{\prime}(W) n_{y} \\
& +\beta \sigma^{2} \tau^{2} \hat{e}^{2} \sigma_{W}^{2} W^{2} V^{\prime \prime}(W) n_{y}^{2} \\
& +n_{k}^{2}\left(\sigma_{W^{k}}^{2}+\sigma_{W^{f}}^{2}\right) W^{2} V^{\prime \prime}(W) \\
& +n_{k}\left[\left[r_{k}-\left(i^{*}+\pi\right)\right] W V^{\prime}(W)-\sigma_{W^{f}}^{2} W^{2} V^{\prime \prime}(W)\right]=0
\end{aligned}
$$

or

$$
\begin{aligned}
& (1-\mu)\left(\sigma_{W^{k}}^{2}+\sigma_{W^{f}}^{2}\right) n_{k}^{2} \\
& +\left[-\left[r_{k}-\left(i^{*}+\pi\right)\right]-(1-\mu) \sigma_{W^{f}}^{2}\right] n_{k} \\
& -\beta[1-\tau+\bar{x} \tau \hat{e}] n_{y}+(1-\mu) \beta \sigma^{2} \tau^{2} \hat{e}^{2} \sigma_{W^{W}}^{2} n_{y}^{2}=0 .
\end{aligned}
$$

This is a second-order differential equation in $n_{k}$. The discriminant is

$$
\begin{aligned}
\Delta= & {\left[r_{k}-i^{*}-\pi+(1-\mu) \sigma_{W^{f}}^{2}\right]^{2} } \\
& -4(1-\mu)\left(\sigma_{W^{k}}^{2}+\sigma_{W^{f}}^{2}\right)\left[(1-\mu) \beta \sigma^{2} \tau^{2} \hat{e}^{2} \sigma_{W^{W}}^{2} n_{y}^{2}-\beta[1-\tau+\bar{x} \tau \hat{e}] n_{y}\right] .
\end{aligned}
$$

Considering the solutions for $\triangle>0$, we obtain:

$$
n_{k}^{1,2}=\frac{r_{k}-\left(i^{*}+\pi\right)+(1-\mu) \sigma_{W^{f}}^{2} \pm \sqrt{\triangle}}{2(1-\mu)\left(\sigma_{W^{k}}^{2}+\sigma_{W^{f}}^{2}\right)} .
$$

Among both solutions, the following one satisfies the condition $n_{k}>0$ :

$$
n_{k}=\frac{r_{k}-\left(i^{*}+\pi\right)+(1-\mu) \sigma_{W^{f}}^{2}+\sqrt{\triangle}}{2(1-\mu)\left(\sigma_{W^{k}}^{2}+\sigma_{W^{f}}^{2}\right)} .
$$

The household's optimal choice is therefore described by the following 
system :

$$
\left\{\begin{array}{l}
\hat{C}=(\delta \mu)^{\frac{1}{\mu-1}} P^{\frac{1-\eta}{\mu-1}} W \\
\hat{e}=\frac{\bar{x} \tau \hat{n}_{k}^{\beta} n_{g}^{1-\beta}\left(\frac{T}{W}\right)^{1-\beta}}{(1-\mu)\left(\sigma \tau \hat{n}_{k}^{\beta} n_{g}^{1-\beta}\left(\frac{T}{W}\right)^{1-\beta} \sigma_{W W}\right)^{2}} \\
n_{k}=\frac{r_{k}-\left(i^{*}+\pi\right)+(1-\mu) \sigma_{W f}^{2}+\sqrt{\triangle}}{2(1-\mu)\left(\sigma_{W^{k}}^{2}+\sigma_{W f}^{2}\right)} \\
n_{f}=n_{k}-1
\end{array}\right.
$$

\section{Appendix C. Transversality conditions}

The agents' choices must also satisfy the transversality condition. We consider this condition for the consumer (the proof is similar for the government).

For the constant elasticity utility function, the transversality condition is given by:

$$
\lim _{t \rightarrow \infty} \mathbb{E}\left[W(t)^{\mu} e^{-\rho t}\right]=0 .
$$

The stochastic differential equation in $\mathrm{W}$ is

$$
d W(t)=\psi^{W} W(t) d t+\sigma_{z^{W}} W(t) d z^{W}(t)
$$

$\psi^{W(t)}$ and $\sigma_{z^{W(t)}} d z^{W}(t)$ (defined by Equations (35) and (36)) converge to constant terms when when $t \rightarrow \infty$, so we omit $t$. We first compute the solution of C.2 for $W(0)=w_{0}$ (initial condition of wealth), given.

We rewrite C.2 as follows

$$
\frac{d W(t)}{W(t)}=\psi^{W} d t+\sigma_{z^{W}} d z^{W}(t)
$$

Integrating this equation between 0 and $\mathrm{t}$ gives

$$
\int_{0}^{t} \frac{d W(u)}{W(u)}=\int_{0}^{t} \psi^{W} d u+\int_{0}^{t} \sigma_{z^{W}} d z^{W}(u)=\psi^{W} t+\sigma_{z^{W}} z^{W}(t) .
$$

We use Itô's formula:

$$
d f(t, W(t))=\frac{\partial f(t, W(t))}{\partial t} d t+\frac{\partial f(t, W(t))}{\partial W} d W(t)+\frac{1}{2} \frac{\partial^{2} f(t, W(t))}{\partial W^{2}}(d W(t))^{2}
$$


Taking $f(t, W(t))=f(W)=\ln (W)$, we obtain

$$
d \ln (W(t))=\frac{d W(t)}{W(t)}-\frac{1}{2}\left[\frac{d W(t)}{W(t)}\right]^{2} .
$$

Since $\left[d z^{W}(t)\right]^{2}=d t, d t^{2}=0$ and $d z^{W}(t) \cdot d t=0$, we have

$$
\left[\frac{d W(t)}{W(t)}\right]^{2}=\left[\psi^{W} d t+\sigma_{z^{W}} d z^{W}(t)\right]^{2}=\sigma_{z^{W}}^{2} d t .
$$

Thus,

$$
d \ln (W(t))=\frac{d W(t)}{W(t)}-\frac{\sigma_{z^{W}}^{2}}{2} d t .
$$

And integrating between 0 and $t$, we have

$$
\ln (W(t))-\ln \left(w_{0}\right)=\int_{0}^{t} \frac{d W(u)}{W(u)}-\frac{\sigma_{z^{W}}^{2}}{2} t .
$$

Replacing by the expression in C.4, we get

$$
\ln \left(\frac{W(t)}{w_{0}}\right)+\frac{\sigma_{z^{W}}^{2}}{2} t=\int_{0}^{t} \frac{d W(u)}{W(u)}=\psi^{W} t+\sigma_{z^{W}} z^{W}(t),
$$

and thus

$$
W(t)=w_{0} \exp \left[\left(\psi^{W}-\frac{\sigma_{z^{W}}^{2}}{2}\right) t+\sigma_{z^{W}} z^{W}(t)\right],
$$

which yields to

$$
W(t)^{\mu} \exp (-\rho t)=w_{0}^{\mu} \exp \left[\left(\mu \psi^{W}-\frac{\mu \sigma_{z^{W}}^{2}}{2}-\rho\right) t+\mu \sigma_{z^{W}} z^{W}(t)\right] .
$$

This is a geometric brownian motion. Assuming $z^{W}(t)$ is independent of $w_{0}$, one of the properties of such a motion is that,

$$
\mathbb{E}\left[W(t)^{\mu} \exp (-\rho t)\right]=\mathbb{E}\left[w_{0}^{\mu}\right] \exp \left[\left(\mu \psi^{W}-\rho\right) t\right] .
$$

In the end, the transversality condition can be rewritten as

$$
\lim _{T \rightarrow \infty} \mathbb{E}\left[w_{0}^{\mu}\right] \exp \left[-\left(\rho-\mu \psi^{W}\right) T\right]=0 .
$$

This puts a lower bound on the rate of impatience $\rho$, since the above condition is satisfied for $\rho>\mu \psi^{W}$. 
For the government, the transversality condition is obtained in a similar way and implies that $\rho>\gamma \psi^{T}$ with $\psi^{T}$ is defined by Equation(24).

\section{References}

Adler, G., Sosa, S., 2013. External conditions and debt sustainability in Latin America. IMF Working Papers 13/27, International Monetary Fund.

Aguiar, M., Amador, M., 2014. Sovereign debt. Elsevier, North-Holland, Ch. 11, pp. 647-687, published in Handbook of International Economics, edited by G. Gopinath, E. Helpman and K. Rogoff.

Alm, J., 2012. Measuring, explaining, and controlling tax evasion: lessons from theory, experiments, and field studies. International Tax and Public Finance 19(1), 54-77.

Arellano, C., 2008. Default risk and income fluctuations in emerging economies. American Economic Review 98, 690-712.

Asonuma, T., 2016. Serial sovereign defaults and debt restructurings. IMF Working Papers 16/66, International Monetary Fund.

Berg, A., Patillo, C., 1999. Predicting currency crises: the indicators approach and an alternative. Journal of International Money and Finance 18(4), 561-586.

Boonman, T., Jacobs, J., Kuper, G., 2014. Currency crises in Mexico, 19902009: an early warning system approach, 2014th Edition. Universidad de Guadalajara, Guadalajara, Mejico, Ch. 2, pp. 34-51, published in Nonlinear time series and finance, edited by S. Cornado-Ramirez, P.L. CelsoArellano, C.O. Trejo-Pech.

Bourguignon, F., 1974. A particular class of continuous time stochastic growth model. Journal of Economic Theory 9(2), 141-158.

Célimène, F., Dufrénot, G., Mophou, G., N'Guérétaka, G., 2016. Tax evasion, tax corruption and stochastic growth. Economic Modelling 52(A), 251-258.

Chang, F.-R., 2004. Stochastic optimization in continuous time. Cambridge University Press. 
Chang, F.-R., Maliaris, A., 1987. Asymptotic growth under uncertainty. Existence and uniqueness. Review of Economic Studies 54(1), 169-174.

Ciarlone, A., Trebeschi, G., 2005. Designing an early warning system for debt crises. Emerging Market Review 6, 376-395.

Clauset, A., Shalizi, C. R., Newman, M. E. J., 2009. Power-law distributions in empirical data. SIAM Review 51(4), 661-703.

Feller, W., 1952. The parabolic differential equation and the associated semigroup of transformations. Annals of Mathematics 55, 468-519.

Feller, W., 1954. Diffusion processes in one dimension. Transactions of the American Mathematical Society 97, 1-32.

Gabaix, X., 2009. Power laws in economics and finance. Annual Review of Economics 1, 255-293.

Gabaix, X., Ibragimov, R., 2011. Rank-1/2: a simple way to improve OLS estimation of tail exponents. Journal of Business and Economic Statistics 29(1), 24-39.

Herrera, S., Garcia, C., 1999. A user guide to an early warning system for macroeconomic vulnerability in Latin American countries. Policy Research Working Paper 2233, World Bank.

Ito, K., McKean, H., 1996. Diffusion processes and their sample paths. Springer Verlag.

Jenkinson, A. F., 1955. The frequency distribution of the annual maximum (or minimum) values of meteorological elements. Quarterly Journal of the Royal Meteorological Society 81, 158-171.

Jensen, B. S., Richter, M., 2007. Stochastic One-Sector and Two-Sector Growth Models in Continuous Time. Copenhagen Business School Press, Denmark, Ch. 5, pp. 167-216.

Kamin, S. B., Babson, O. D., 1999. The contribution of domestic and external factors to Latin American devaluation crises: an early warning approach. International Finance Discussion Paper 645, Board of governors of the Federal Reserve System. 
Kaminsky, G., Reinhart, C., 1999. The twin crises: the causes of banking and balance of payment problems. American Economic Review 89(3), 473-500.

Kaminsky, G., Reinhart, C., Vegh, C., 2005. When it rains, it pours: procyclical capital flows and macroeconomic policies. NBER, pp. 11-53, published in HNBER Macroeconomics Annual 2004, edited by Mark Gertler and Kenneth Rogoff.

Manasse, P., Roubini, N., 2009. Rules of thumb for sovereign debt crises. Journal of International Economics 78, 192-205.

Merton, R., 1975. An asymptotic theory of growth under uncertainty. Review of Economic Studies 42, 375-393.

Murphy, K., 2008. Enforcing tax compliance: to punish or persuade? Economic Analysis and Policy 138(1), 113-135.

Reinhart, C., Rogoff, K., 2008. This time is different: a panoramic view of eight centuries of financial crises. NBER Working Papers 13882, NBER.

Reinhart, C., Rogoff, K., 2011. From financial crash to debt crisis. American Economic Review 101(5), 1676-1706.

Reinhart, C., Rogoff, K., 2013. Banking crises: an equal opportunity menace. Journal of Banking and Finance 37(11), 4557-4573.

Savona, R., Vezzoli, M., 2015. Fitting and forecasting sovereign defaults using multiple risk signals. Oxford Bulletin of Economics and Statistics 77(1), 66-92.

Slemrod, J., 2007. Cheating ourselves: the economics of tax evasion. The Journal of Economic Perspectives 24, 25-48.

Tanner, E., Samake, I., 2008. Probabilistic sustainability of public debt: a vector autoregression approach for Brazil, Mexico and Turkey. IMF Staff Papers 55(1), 149-182.

Turnovsky, S. J., 1999. On the Role of Government in a Stochastically Growing Open Economy. Journal of Economic Dynamics and Control 23, 873908.

Turnovsky, S. J., 2000. Methods of macroeconomic dynamics. MIT Press. 